\title{
ALIMENTAR LA RED URBANA: LAS VILLAS Y CIUDADES \\ PORTUARIAS DEL ALGARVE Y EL ABASTECIMIENTO \\ CEREALISTA A FINALES DE LA EDAD MEDIA
}

\section{FEEDING AN URBAN NETWORK: GRAIN SUPPLY TO THE Algarve Port TOWNS IN THE LATE MidDle AgES}

\author{
GONÇALO MELO DA SILVA \\ goncalosilva1989@hotmail.com \\ UNIVERSIDADE NOVA DE LISBOA ${ }^{1}$ \\ http://dx.doi.org/10.25267/Riparia sup.2019.i2.08
}

\section{RESUMEN}

En Portugal, las hambrunas, las crisis alimentarias y el abastecimiento cerealista de las villas y ciudades constituyen un campo prometedor, pero poco trabajado, a pesar de los trabajos pioneros de algunos historiadores. Este trabajo pretende contribuír a conocer la capacidad de los núcleos urbanos portuarios del Algarve para responder a las crisis cerealistas y garantizar el abastecimiento de cereales. En este sentido, presentaremos los primeros resultados de la investigación sobre las crisis cerealistas que las villas y ciudades portuarias del Algarve sufrieron; las estrategias que los gobiernos municipales utilizaron para combatir este problema; y, por último, reflexionar sobre sus efectos y el grado de éxito de sus políticas.

\footnotetext{
1 Bolseiro de doutoramento da Fundação para a Ciência e Tecnologia (SFRH/BD/85931/2012). Instituto de Estudos Medievais. Faculdade de Ciências Sociais e Humanas, Av. de Berna, 26 C, Edifício I\&D $2^{\circ}$ piso, Sala 221. 1069-061 Lisboa, Portugal.

G. M da Silva, «Alimentar la red urbana: las villas y ciudades portuarias del Algarve y el abastecimiento cerealista a finales de la Edad Media», Suplemento RIPARIA 2 (2019), 211-247.
} 
Palabras Claves: historia urbana, crisis alimentarias, gobernanza municipal, comercio de cereales, poder régio.

\section{Abstract}

In Portugal, famines, food crises and the cereal supply of the medieval towns represent a rich and promising field of studies, which is still little explored, in spite of the pioneering works of some historians. Thus, this work aims to contribute to know the capacity of Algarve port towns to respond to cereal crises and ensure the supply of this product. In this sense, I will present the first results of the research on the cereal crises suffered by Algarve port towns; the strategies that the municipal governments used to solve this problem, and, finally, reflect on its effects and the degree of success of its policies.

KEY WORDS: urban history, provisioning medieval, municipal government, cereal trade, royal power. 


\section{Introducción}

Durante el período medieval, una de las principales tareas, objetivos y, a menudo, preocupaciones de los gobiernos municipales era garantizar un harto y rico abastecimiento de sus localidades, especialmente de los bienes de primera necesidad y sobre todo, de los productos alimenticios, indispensables para la supervivencia humana ${ }^{2}$. A pesar de ello, la carencia de alimentos o la hambruna eran habituales en la vida de las poblaciones ${ }^{3}$.

De acuerdo con los trabajos de François Menant ${ }^{4}$, Pere Benito i Monclús ${ }^{5}$ y Luciano Palermo ${ }^{6}$, la carencia de alimentos estaba normalmente ligada a una crisis cerealista. La escasez de este producto llevaba a una subida rápida y brusca de los precios de este y, en consecuencia, de otros productos. Por su parte, el

2 I. GONÇALVES, «Defesa do consumidor na cidade medieval: os produtos alimentares (Lisboa - séculos XIV e XV)», Um olhar sobre a cidade medieval, Cascais 1996, 97 - 116; I. GONÇALVES, «A propósito do pão da cidade na Baixa Idade Média», en C. G. da SILVA (coord.), en Turres Veteras IX. História da Alimentação, Torres Vedras, 2007, 49- 72.

3 A. H. de O. MARQues, Introdução à história da agricultura em Portugal. A questão cerealifera durante a Idade Média, Lisboa 1968, 39-46, 257-282; A. H. de O. MARQUeS, Portugal na Crise dos Séculos XIV e XV, vol. IV de J. SERRÃO y A. H. de O. MARQUES, (Dirs.), Nova História de Portugal, Lisboa 1987, 30; M. J. P. F. TAVArES, «Os sinais dos tempos: Para o estudo do clima e do litoral português», en A. A. TAVARES et al. (eds.), Evolução geohistórica do litoral português e fenómenos correlativos: geologia, história, arqueologia e climatologia: actas do Colóquio, Lisboa, 3 e 4 de junbo de 2004, Lisboa 2004, 499-515; S. C. FerreIrA, Preços, Salários e Niveis de Vida em Portugal na Baixa Idade Média, Porto: s.n, 2014, Doutoramento em História apresentado à FLUP, policopiado, 80-143. Consúltese el Figura 2.

4 F. Menant, «Crisis de subsistencia y crisis agrarias en la Edad Media: algunas reflexiones previas», en H. R. Oliva Herrer y P. Benito i Monclús, (coord.), Crisis de subsistencia y crisis agrarias en la Edad Media, Sevilla 2007, 20-22.

5 P. Benito i Monclús, «Fams i caresties a la Mediterrània occidental durant la baixa edat mitjana: el debat sobre les crisis de la crisi», Recerques: Història, economia i cultura, 49, 2004, 179-193; P. BENito I Monclús, «Las crisis alimenticias en la Edad Media: carácteres generales, distinciones y paradigmas interpretativos», en E. LOPEZ OJEDA, Comer, beber, vivir: consumo y niveles de vida en la Edad Media Hispánica. Logroño 2011, 127 130.

${ }^{6}$ Luciano PALERMO, «Di fronte alla crisi: l'economia e il linguaggio della carestia nelle fonti medieval», en P. BENito i Monclús (coord.), Crisis alimentarias en la Edad Media: modelos, explicaciones y representaciones. Lleida 2013, 47-67. 
hambre (fome) aparecía en la fase más grave de los períodos de carestía, cuando el sistema de abastecimiento colapsaba y acababa por provocar el aumento de la mortalidad: habitualmente causada por inanición o por las patologías que atacaban los cuerpos debilitados por la falta de alimentos. Sin embargo, como los mismos investigadores advierten, la documentación medieval no siempre nos permite distinguir y separar con precisión los períodos de carencia de alimentos de los de las hambrunas.

En Portugal, a pesar de los trabajos pioneros de autores, como Oliveira Marques ${ }^{7}$, Iria Gonçalves ${ }^{8}$ y Maria Helena Coelho Cruz $^{9}$, los historiadores no han mostrado mucho interés en las hambrunas y las crisis alimentarias, lo que significa que siguen siendo necesarios estudios sobre, por ejemplo, la reacción del poder real y concejal a las crisis alimentarias; las medidas que tomaban para combatir el azote del hambre; la capacidad de las autoridades políticas para implementar sus decisiones; y si las decisiones tomadas ayudaban a resolver las crisis alimentarias o, por el contrario, contribuían a agravarlas. En el caso de las villas y ciudades portuarias, todavía no sabemos si el abastecimiento marítimo pudo colmar las faltas de cereales.

Este trabajo pretende contribuir a conocer la capacidad de las villas y ciudades portuarias del Algarve para responder a las crisis ceralíferas. En este sentido, presentaremos los primeros resultados de la investigación sobre las crisis cerealistas que las villas y ciudades portuarias del Algarve sufrieron, las estrategias que utilizaron para combatir este problema y, por último, reflexionar sobre sus efectos y el grado de éxito de sus políticas.

\footnotetext{
7 A. H. de O. MARQues, Introdução à história da agricultura ..., 21-285.

8 I. GonÇAlves, Defesa do consumidor..., 97-116; I. GonÇALVES, «A propósito do pão...», 49- 72; I. GONÇALVES, À mesa nas terras de Alcobaça em finais da Idade Média. Alcobaça 2017.

${ }_{9}^{9}$ M. H. da C. Coelho, O Baixo Mondego nos finais da Idade Média. 2 vols. Lisboa 1989.
}

«Alimentar la red urbana: las villas y ciudades portuarias del Algarve...» 


\section{Las raíces de una amenaza: Las crisis frumentarias en las villas y ciudades portuarias del Algarve (siglos XIV-XVI)}

A finales de la Edad Media, el Algarve contaba con trece localidades portuarias: Aljezur, Sagres, Lagos, Alvor, Portimão, Silves, Albufeira, Loulé, Faro, Tavira, Cacela, Castro Marim y Alcoutim (Fig. 1). Los centros urbanos portuarios del Algarve eran comunidades con una dimensión pequeña o media en el contexto del reino ${ }^{10}$. La consulta del Numeramento de 1527-1532, aunque algo tardía, muestra que Tavira tenía aproximadamente 2045 fuegos urbanos, Lagos 1310, Faro 873, Loulé 536, Silves 271, Albufeira 194 y Castro Marim 125 ${ }^{11}$. Los núcleos urbanos portuarios del Algarve eran pequeñas villas dentro de la órbita política de la Corona, de las órdenes militares - como la orden de Avis, Cristo y, sobre todo, Santiago ${ }^{12}-$ y desde el siglo XV, de algunas casas nobiliarias vinculadas a la expansión norteafricana como los Meneses - o al servicio cortesano - como los Andrade, los Coutinho y los Castelo Branco.

Entre los siglos XIV y XVI, todos los núcleos urbanos parecían apostar mayoritariamente por la producción de fruta, sobre todo seca, y de vino, con actividades asociadas como la producción de esparto, en los casos de Silves y Loulé, la pesca, en Lagos, Portimão y Faro, o los fletes marítimos, en Portimão y Tavira. Estas actividades ayudaban a alimentar un importante comercio marítimo con Castilla (sobre todo Andalucía), Flandes, Inglaterra, Aragón, Bretaña, Norte de África y la Península Itálica.

10 G. M. da SiLva, «Un poder que viene del Mar Océano: Las Cofradías de los Hombres del Mar en el Algarve a fines de la Edad Media», en J. Solórzano TElECHEA et al. (eds.), Las sociedades portuarias de la Europa Atlántica en la Edad Media. Logroño 2016, 119.

11 Visconde de Santarém, Alguns documentos para servirem de provas à parte $1^{a}$ das memorias para a história, e theoria das cortes gerias, que em Portugal se celebrarão pelos três estados do reino ordenadas no anno de 1824. Lisboa 1828, 105.

12 G. M. da SILvA, «A Coroa, as vilas e o mar: A rede urbana portuária do Algarve (1266-1325)», en Adelaide Millán da COSTA et al., O papel das pequenas cidades na construção da Europa Medieval, Lisboa 2017, 518-526. 
Las villas y las ciudades del Algarve importaban varios productos de fuera de la región, entre los cuales, por su importancia, destacaban los cereales, solo de lejos seguidos por los textiles y los productos manufacturados ${ }^{13}$, lo que nos hace suponer que el abastecimiento del pan cotidiano era sin duda un problema y una preocupación constante.

De acuerdo con los datos compilados por Oliveira Marques, Maria José Ferro Tavares y Sérgio Ferreira, entre 1302 e 1521, Portugal parece registrar, por lo menos, 94 años de escasez de alimentos o hambrunas ${ }^{14}$. No todas las crisis alimentarias dieron origen a hambrunas generalizadas en todo el reino, como fueron las de 1333, 1380, 1381, 1402, 1412-1413, 1437-1441, $1463,1484-1487^{15}$, ya que cada región presentaba características geográficas e capacidades de abastecimiento distintas, según los propios mercados a los que podían recurrir ${ }^{16}$. Las villas y las ciudades portuarias del Algarve estaban normalmente bien provistas de pescado, vino, fruta y sal, pero la carne era cara, sobre todo en el siglo $\mathrm{XV}^{17}$, y faltaba el pan, el alimento indispensable de todas las comidas, cuya ausencia era difícil de

13 J. R. Magalhães, O Algarve económico durante o século XVT. Lisboa 1970; L. A. da FOnSECA y J. A. S. M. PIZARro, «Algumas considerações sobre o comércio externo algarvio na época medieval», en Actas das I Jornadas de História Medieval do Algarve e Andaluria, Loulé: UAlg 1987, 61-89; L. A. da FONSECA, «O Algarve da Reconquista à conjuntura depressiva do século XIV», en M. da G. MARQUES (dir.), O Algarve da antiguidade aos nossos dias: elementos para a sua história. Lisboa 1999, 115-122.

14 A. H. de O. MARQUeS, Introdução à bistória da agricultura..., 39-46, 257-282; A. H. de O. Marques, Portugal na Crise dos Séculos XIV e XV ..., 30; M. J. P. F. Tavares, «Os sinais dos tempos...», 499-515; S. C. Ferreira, Preços, Salários e Niveis de Vida..., 80143. Consúltese el Figura 2.

15 A. H. de O. MARQues, Introdução à história da agricultura..., 43, 44, 45, 265-267, 277 279; M. J. P. F. TAVARES, «Os sinais dos tempos...», 501, 505, 506, 508, 509; S. C. Ferreira, Preços, Salários e Niveis de Vida..., 85-86, 99-101, 105-108, 116-120, 126, 132 138.

16 A. H. de O. Marques, Introdução à história da agricultura..., 61-88; A. H. de O. Marques, Portugal na Crise dos Séculos XIV e XV..., 30; S. C. Ferreira, Preços, Salários e Niveis de Vida..., 91.

17 S. C. Ferreira, Preços, Salários e Niveis de Vida..., 181-187.

«Alimentar la red urbana: las villas y ciudades portuarias del Algarve...» 
suprimir y significaba casi siempre el hambre ${ }^{18}$. De hecho, en todo el reino, después de Lisboa, estos centros urbanos fueron los que más sufrieron la escasez de cereales ${ }^{19}$.

En efecto, entre 1338 y 1514, en los núcleos urbanos portuarios del Algarve, la documentación consultada registra 35 años con crisis alimentarias, concretamente por escasez de cereal: 27 coinciden con hambrunas generales en todo el reino y 9 parecen, hasta el momento, haber ocurrido sólo en el Algarve ${ }^{20}$. Sin embargo, el número de años deficitarios en cereal fue ciertamente mucho mayor. Desde luego, la región se vio probablemente afectada por otras crisis cerealistas que se extendieron por todo el reino, aunque no esté documentado ${ }^{21}$. Además, el Algarve, como presentaba una productividad cerealista muy baja, dependía de otros mercados para garantizar su abastecimiento, los cuales no siempre lograron responder a sus demandas, como veremos más adelante ${ }^{22}$.

En los centros urbanos portuarios del Algarve, el número de años con referencias a escasez de cereal o hambrunas sigue la misma tendencia registrada en el resto del reino, siendo mayor en el siglo XV que en el $\mathrm{XIV}^{23}$. De todas las crisis de cereales, las de 1352, las de la década de 1380 del siglo XIV, las de 1455 y las de 1468 parecen haber sido las más graves debido a las medidas adoptadas, como veremos más adelante. Los más flagelados por

\footnotetext{
18 Para Portugal, consúltese, entre otros, sobre la importancia del pan y del cereal en la alimentación medieval portuguesa: A. H. de O. MARQues, Introdução à história da agricultura..., 226-230; M. H. da C. CoelHo, O Baixo Mondego..., vol. 1, 130-152, 691702; I. GONÇALVES, «Defesa do consumidor...», 97 - 116; I. GONÇALVES, «A propósito do pão...», 49- 72; I. GonÇALVES, À mesa nas terras..., 101-163.

19 A. H. de O. Marques, Introdução à história da agricultura..., 213, 240, 259-282; S. C. Ferreira, Preços, Salários e Niveis de Vida..., 142.

${ }^{20}$ Consúltese el Figura 2.

21 Consúltese el Figura 2.

22 Leia-se sobre isso o que redigimos mais adiante.

23 Consúltese el Figura 2.
} 
la falta de cereal fueron Faro, Silves, Lagos y, principalmente, Loulé y Tavira ${ }^{24}$.

Las crisis cerealistas en el Algarve, como ocurría en otras regiones portuguesas ${ }^{25}$ y europeas ${ }^{26}$, fueron desencadenadas, desde luego, por factores endógenos de la región. Aunque el cereal se cultivaba un poco por todas partes, los suelos algarvíos no eran propicios para su cultivo, y las únicas áreas capaces de asegurar una cierta productividad se circunscribían a los suelos aluviales, las tierras menos secas depositadas en los valles de los ríos, como el Guadiana, y de las riberas que cruzaban la región, como las de Bensafrim, Quarteira y Asseca. En el período medieval, el rendimiento del cereal aún estaba más limitado ${ }^{27}$, debido, al igual que en otras regiones, a la utilización de técnicas e instrumentos agrícolas rudimentarios, a la carencia o poca eficacia de los fertilizantes disponibles y, a los efectos de las inclemencias de la naturaleza. Los resultados de las cosechas se vieron perjudicados debido a condiciones climáticas adversas, sobre todo sequías, como las registradas en 1385 y $1396^{28}$.

Una mala cosecha era el primer paso para una carestía, pero podía, a veces, representar solo un pretexto para una. De

\section{${ }^{24}$ Consúltese el Figura 2.}

25 A. H. de O. MARQUeS, Introdução à história da agricultura..., 257-281; S. C. FERREIRA, Preços, Salários e Niveis de Vida..., 80-143.

26 F. Menant, «Crisis de subsistencia y crisis...», 37-44; P. BEnito i MonCLús, «De Labrousse a Sen. Modelos de causalidad y paradigmas interpretativos de las crisis alimentarias preindustriales», en P. BENITO I MONCLÚs (coord.), Crisis alimentarias en la Edad Media: modelos, explicaciones y representaciones, Lleida 2013, 47-67; H. R. OLIVA HERRER, «Carestía y lucha política en Castilla durante el siglo XV», Anuario de Estudios Medievales, 46, 2, 2016, 899-937.

27 J. R. MAgalHães, O Algarve económico..., 55-56; M. T. MALTEZ, Os recursos alimentares no Algarve Oriental (século XIV). Lisboa: s.n., 1993, Dissertação de mestrado em História Medieval apresentada à FCSH/UNL, policopiada, 10, 30.

${ }^{28}$ En 1385 e 1396, em Loulé, la falta de pan parece ser causada por una sequía. A. H. de O. MARques, Introdução à história da agricultura..., 43, M. J. P. F. TAvares, «Os sinais dos tempos...», 504-505; Actas de Vereação de Loulé. Séculos XIV-XV. Separata da Al'ulyã: Revista do Arquivo Histórico Municipal de Loulé, Loulé 1999-2000, 29.

«Alimentar la red urbana: las villas y ciudades portuarias del Algarve...» 
esta forma, anticipando la escalada de precios, algunos labradores, comerciantes y otros agentes intermediarios retenían el cereal en sus almacenes, colocándolo a la venta en pequeñas cantidades y con precios elevados. Así, la carestía no era producto de la efectiva falta de cereal, sino de la imposibilidad de comprarlo, debido a las prácticas especulativas. Este fue el caso de Loulé, en 1385 y1455 ${ }^{29}$.

A partir de la segunda mitad del siglo XV, el crecimiento poblacional $y$, por consiguiente, el aumento del consumo de cereales, reforzó el déficit de cereal de la región y la dependencia del trigo importado, sobre todo en los núcleos urbanos más poblados del Algarve, como Lagos y Tavira. Incluso en años de cosecha normal, sus gobernantes y los principales oficiales regios de la comarca sabían que estos núcleos urbanos necesitaban el cereal que venía de fuera para garantizar su supervivencia. En efecto, en 1514, en un año sin referencias a malas cosechas, el corregidor escribía al monarca que: vossa vila de Lagos é lugar que recebia grande dano se a ela não viessem pão de vossos reinos e senhorios per mar e de fora deles, do qual os reis passados e vossa alteza lhe fez sempre

29 En 1385, cuando fijaron el precio del pan, las autoridades de Loulé refieren que muitos solamente queriom poer o pam tam caro (...) os que tinham ho pam na vila ante o queriiom vender pera fora parte que aos da vila, Actas de Vereação de Loulé. Séculos XIV-XV..., 29-30. En 1455, cuando ya hacía tres años que faltaban el cereal y la carne, en las cortes de Lisboa, el concejo de Loulé se quejaba al monarca de que el contador, el almojarife y los recibidores cogían el pan pagado por el concejo que estaba en las tiendas, diciendo que tenían por encargo para servicio del rey. Cuando la noche llegaba, se repartieron entre si e per quem lhes apraz e deles o tornam a revender per maior preço dessa guisa o fazem as carnes quando são poucas que as repartem as arrobas (...) e assim a terra era toda desgovernada e 0 povo passa mal e vai-se tudo a perdição. Arquivo Nacional da Torre do Tombo (en adelabte ANTT), Chancelaria de D. Afonso V, liv. 15, fl. 144v. En el mismo año, también en las cortes de Lisboa, el concejo de Faro se quejaba a Afonso V que, cuando llegava el Invierno y la Cuaresma y había menos peces para pescar, los oficiales regios cogían dos o tres cestos de pescado, diciendo que $o$ hão mister e dão com eles em uma casa e o repartem em montes entre si e per outros a que dar querem per guisa que ao povo não the fica nada nem os almocreves não hão vontade tornarem mais com o dito pão e assim ficais de todo famintos e sois assim por eles mais torvados porque não podeis por este modo e causa haver os ditos mantimentos pera adubio de vossos bens que a nós tanto rendem por trazerem essa partiga os ditos nossos oficiais como trazem emno trigo e na carne a quando mister. ANTT, Chancelaria de D. Afonso V, liv. 15, fl. 146. 
mercê da dízima dele e de todos os legumes que a ela vinham (...) a qual mercê sempre se ressalvo de 10 em 10 anos $^{30}$.

No obstante, las crisis de cereales también podían ser desencadenadas por factores exógenos, capaces de afectar los circuitos de abastecimiento o la capacidad habitual de los mercados en el proveimiento del precioso cereal ${ }^{31}$. Este panorama aparece documentado en el Algarve, cuyos núcleos urbanos tuvieron, algunas veces, dificultades en adquirir cereal en los mercados donde lo solían hacer, desde los centros urbanos del Alentejo, como Serpa, Moura, Beja y Évora, a la vecina Andalucía, tanto porque los habitantes de estos lugares temían o, incluso, sufrían también períodos de carestía de cereal, como por los conflictos que perturbaban los circuitos comerciales que los unían $^{32}$. En 1477, durante la guerra luso-castellana, en las cortes de Montemor-o-Novo, las villas del Algarve se quejaron al monarca de que la carencia de pan era aún mayor, una vez que Moura, Serpa, y Beja no tenían cereales para venderles y no llegaba cereal alguno de Andalucía, donde sempre este reino bouve e havia grande provisão ${ }^{33}$. No será desdeñable considerar que este escenario, especialmente la falta de trigo andaluz, se haya verificado regularmente a causa de los conflictos militares entre Portugal y Castilla.

Además, el esfuerzo de expansión territorial en el Norte de África y de manutención de las respectivas plazas acabó

\footnotetext{
30 ANT'T, Gavetas, Gaveta XX, maço 2, nº 65

31 F. Menant, «Crisis de subsistencia y crisis...», 44; P. Benito i Monclús, «De Labrousse...», 47-67; H. R. Oliva Herrer, «Carestía y lucha política...», 899-937.

32 En 1374, cuando una hambruna afecta a todo el reino, las villas de Beja y Serpa, donde Tavira solía adquirir cereal, prohíben la salida de este, ACMT, Reforma dos Tombos, tomo 1, fl. 90-90v. En el siglo siguiente, en 1468, cuando hubo otra hambruna general, la misma villa se quejaba de que Évora, Beja y otros lugares del reino no querían vender pan por dineros. Es probable que estas medidas hayan sido implementadas durante otras hambrunas generales, ANTT, Leitura Nova, Livro 3 do Guadiana, fl. 29. ANTT, Cortes, maço 2, no 14, fls. 142-142v (1477).

33 ANTT, Cortes, maço 2, no 14, fls. 142-142v (1477).
}

«Alimentar la red urbana: las villas y ciudades portuarias del Algarve...» 
también por afectar, en diversas ocasiones y por distintas vías, el abastecimiento cerealista del Algarve. Las quejas de los concejos algarvios corresponden sobre todo a la segunda mitad del siglo $\mathrm{XV}$, evocando, a este propósito: el reclutamiento de labradores para los socorros enviados a las plazas portuguesas en Marruecos ${ }^{34}$, la confiscación de embarcaciones para transportar cereal desde los Azores a estos núcleos urbanos ${ }^{35}$, la venta de pescado para Guinea y las islas atlánticas sin traer cereal ${ }^{36} \mathrm{y}$ también, la pérdida o el desvío para Cádiz o Sanlúcar de Barrameda de muchos navíos extranjeros, sobretodo castellanos y bretones, que cambiaban su destino debido a los ataques de las armadas originalmente destinadas al combate contra los moros ${ }^{37}$. Así, la carencia de cereales vivida por el Algarve se veía frecuentemente agravada por factores exógenos que dificultaban su capacidad de abastecerse en otros mercados, nacionales o extranjeros.

\section{3. ¿Apostar por la producción o por la distribución?: las estrategias de los núcleos urbanos algarvios para combatir las crisis de cereales}

La Corona y los gobiernos municipales algarvios, conscientes de los peligros que la falta de pan representaba, implementaron un conjunto diversificado de medidas suplementarias, desde la producción a la comercialización, que se conjugaban y complementaban con el fin de garantizar el abastecimiento regular de cereales a la población por un precio

\footnotetext{
34 ANTT, Chancelaria de D. Afonso V, liv. 13 110v-111 (Tavira 1456), liv. 15, fl. 145 (Loulé, 1455); ANTT, Leitura Nova, Livro 3 do Guadiana, fl. 111-111v (Silves, Faro, Tavira, Loulé, 1457); Biblioteca da Academia de Ciências de Lisboa (en adelante BACL), Reservados, Série Azul, tomo 402, fl. 141-141v (Tavira 1477); A. IriA, O Algarve nas cortes medievais portuguesas do século XV, subsídios para a sua bistória (1404-1449). Lisboa 1990, 299 (Silves, 1444).

35 J. M. da S. MArques, (dirs.), Descobrimentos Portugueses. Documentos para a sua História. Lisboa 1988, Vol. III, 364 (Lagos, 1490).

36 J. M. da S. Marques, (dirs.), Descobrimentos Portugueses..., vol. III, 637 (Lagos, 1482).

37 A. Iria, O Algarve nas cortes medievais..., 232-233.
} 
considerado justo, tan bajo como fuese posible. Las soluciones encontradas son muy similares a las que se practican en otras ciudades, tanto portuguesas ${ }^{38}$, como europeas ${ }^{39}$.

Desde luego, a nivel de la producción, a partir de la segunda mitad del siglo XIV, tal como ocurre en otras villas del reino $^{40}$, los concejos algarvios, con el apoyo regio, procuraron mantener y alargar las áreas de cultivo, sobretodo de cereales, distribuyendo las tierras inexploradas por sus habitantes y empeñándose en garantizar que estas eran aprovechadas ${ }^{41}$. También con el apoyo de los monarcas, agilizaron la adquisición de las propiedades que no eran explotadas por la comunidad musulmana, tanto consiguiendo su entrega para la explotación en régimen de sesmaria ${ }^{42}$, como autorizando su compra por los cristianos $^{43}$. Simultáneamente, a semejanza de otros concejos ${ }^{44}$,

38 A. H. de O. MARQues, Introdução à história da agricultura..., 257-282; I. GONÇALVES, «Defesa do consumidor...», 97 - 116; I. GONÇALVES, «A propósito do pão...», 49- 72.

39 Consúltese sobre esta cuestión: A. RIERA I MELIS, «Crisis frumentarias y políticas municipales de abastecimiento en las ciudades catalanas durante la Baja Edad Media», en H. R. Oliva Herrer y P. Benito i Monclús (coord.), Crisis de subsistencia y crisis agrarias en la Edad Media. Sevilha 2007, 125-160; L. PALERMO; A. FARA y P. BENITO I MONCLÚS (coords.), Políticas contra el hambre y la carestía en la Europa medieval. Lleida 2018.

${ }^{40} \mathrm{~V}$. RAU, Sesmarias medievais portuguesas. Lisboa 1982, 25-26, 50-51, 77, 126-141; A. M. RoDrigues, «The Black Death and Recovery, 1348-1500», en Dulce FreIRE y P. LAINS (eds.), An agrarian history of Portugal, 1000-2000: economic development on the European frontier. Leiden, Boston, 48-49, 51-52.

${ }^{41}$ En 1392, el concejo de Tavira reclamó al monarca diciendo que algunas personas habían recibido matos en sesmaria, pero que no los aprovechaban y no permitían que fuesen explotados por otros individuos sin el pago de una cantidad. El concejo tavirense afirmaba que si los terrenos fuesen trabajados la villa podía contar con major avomdamento de pã que o que ham. Así mismo, Tavira solicitó al rey que las tierras que no fuesen explotadas pudiesen ser atribuidas a los individuos que quisiesen trabajarlas, logrando obtener el parecer favorable del monarca, V. RAU, Sesmarias medievais portuguesas..., 95, 118.

42 En 1361, en las cortes de Elvas, D. Pedro I, a pedido del concejo de Silves, determinó que los almojarifes obligasen a los moros a cultivar las tierras que tenían en Loubite, donde el rey debía recibir la décima de los moros. En el caso de que estos no lo quisiesen hacer, el rey determinaba que las propiedades fuesen aforadas a quien las quisiese trabajar. V. RAU, Sesmarias medievais portuguesas... 116, 163-164.

43 En 1385, el rey, a pedido de Silves, anuló la determinación de D. Fernando que prohibía a los musulmanes vender sus tierras a los cristianos. D. João I repone el

«Alimentar la red urbana: las villas y ciudades portuarias del Algarve...» 
los municipios algarvíos promulgaron posturas o consiguieron privilegios reales con el objetivo de que hubiese mano de obra suficiente para desempeñar las tareas agrícolas ${ }^{45}$, evitar que los labradores fuesen citados por los arrendadores de los derechos fiscales durante las sementeras y $\operatorname{cosechas}^{46} \mathrm{y}$, además, alcanzar condiciones salariales más favorables a los dueños de las tierras ${ }^{47}$.

En el caso de Loulé, el concejo alquiló las tierras que poseía en Bilhas, anteriormente acotadas y destinadas a otros

antiguo costumbre que autorizaba a los cristianos a comprar tierras a los musulmanes, desde que estos pagasen un décimo del precio al monarca, Chancelarias portuguesas: $D$. João I. Edição preparada por J. J. A. DiAs, vol. I, tomo III (1384-1388), 72-73.

44 V. RAU, Sesmarias medievais portuguesas..., 80-91; A. M. RODRIGUES, «The Black Death and Recovery...», 51-53.

45 En 1395, Faro pidió al rey el traslado de un capítulo general de las Cortes de Coimbra (1394), el cual estipulaba que los mancebos de la soldada no fuesen constreñidos a servir con otras personas, como almocrebes, debido a la escasez de mano de obra y a que los serviçais cobraban soldadas y jornales difíciles de satisfacer. F. C. BELOTO, «Pharonensia Monumenta Historica III», Anais do Município de Faro. VI, 1976, 220-222. En el 1400, Silves pidió al monarca que los hijos y mancebos de los labradores no fuesen tomados. A. IRIA, O Algarve nas cortes medievais portuguesas do século XIV (subsídios para a sua história). Lisboa 1982, 115-116. En el 1430, el concejo de Faro pidió la copia de un capítulo general que prohibía a los braceros tener mancebos de soldada, una vez que su contratación por los braceros llevaba a que las elites urbanas se quedasen sin hombres para labrar sus tierras. A. IRIA, O Algarve nas cortes medievais portuguesas do século XV ..., 192-193. En 1436, el rey, a pedido de los concejos de Silves, Tavira, Faro y Loulé, prohibió que los armadores de las embarcaciones reclutasen y contratasen a los mancebos de soldada sin que estos hubiesen cumplido el tiempo de trabajo para el que habían sido contratados anteriormente. F. C. BELOTO, «Pharonensia Monumenta Historica IV - Documentos do século XV», Anais do Município de Faro. VII, 1977, 221. Además, los concejos algarvios pediron varias veces al monarca que los labradores no fuesen reclutados para el ejército y la armada regios. Consúltese por exemplo: ANTT, Chancelaria de D. Fernando, liv. 1, fl. 116v-117. Publicado parcialmente en: Cortes Portuguesas: Reinado de D. Fernando I (1367-1383), Edição preparada por A. H. de O. Marques e N. J. P. P. Dias. Vol. I: 1367-1380. Lisboa 1990, 99; A. IriA, O Algarve nas cortes medievais portuguesas do século XV .., 229 (Silves, 1444)

46 En el 1482, en las cortes de Évora-Viana, Silves pidió al rey que el artículo regio que prohibía a los labradores ser citados por los arrendadores durante el período de las sementeras y cosechas fuese cumplido. ANTT, Chancelaria de D. João II, liv. 2, fl. 5.

${ }^{47}$ Léase sobre isto lo que se ha escrito en la nota 45. 
fines $^{48}$, e impuso pesadas multas sobre los hombres que dañasen las cosechas, muy superiores a las reservadas para los daños infligidos a otros cultivos agrícolas ${ }^{49}$. Debemos considerar que los restantes municipios algarvios pudieran seguir estas prácticas. Pero todo este esfuerzo se enfrentaba necesariamente a la escasez de tierras disponibles y aptas para el cultivo de cereales, en oposición con las que hacían prosperar el cultivo de la viña y de las especies frutícolas, en clara expansión y que alimentaban toda una economía articulada con las redes de comercio nacionales e internacionales.

De ahí que la búsqueda de soluciones para la escasez de cereales pasara sobre todo por la regulación de la comercialización del cereal. En efecto, los poderes municipales del Algarve, al igual que para otros productos, ordenaban que el cereal fuera descargado, almacenado y vendido en determinados lugares, bien conocidos de la población y normalmente de fácil acceso. Los núcleos urbanos más importantes - Lagos, Silves, Loulé y Tavira - señalaban el lugar de descarga con marcos y, muchas veces con el apoyo del monarca, construyeron, ampliaron

\footnotetext{
48 A pesar de las quejas de algunos hombres buenos, en 1402, la edilidad louletana arrendó las tierras que tenía en Bilhas - anteriormente un espacio acotado para pasto de animales, principalmente caballos y yeguas - a particulares que querían cultivar cereal en ellas. El gobierno concejíl arrendó las tierras para pagar la reparación de los muros, torres y veredas de la muralla, pero también intentaría aumentar su producción de cereal, ya que las treguas con Castilla aún no habían sido firmadas y por lo tanto las rutas comerciales con Andalucía tampoco habían vuelto a la normalidad. En el 1423, cuando el hambre arrasaba por todo el reino, el concejo volvió a producir cereal en las tierras de Bilhas, Actas de Vereação de Loulé. Séculos XIV-XV..., 94, 100, 102; Arquivo Municipal de Loulé, PT/AMLLE/AL/CMLLE/E/A/01/liv. 007, Livro de receita $e$ despesa (1423-1425), fl. 12-12v; M. de F. ВОTÃO, A construção de uma identidade urbana no Algarve medieval. O caso de Loulé. Casal da Cambra 2009, 223.

${ }^{49}$ M. Â. BEIRANTE, «Relações entre o homem e a natureza nas mais antigas posturas da câmara de Loulé (séculos XIV-XV)», en Actas das I Jornadas de História Medieval do Algarve e Andaluzia. Loulé 1987, 234-235.
}

«Alimentar la red urbana: las villas y ciudades portuarias del Algarve...» 
y perfeccionaron las estructuras destinadas al almacenamiento y venta del cereal, las alhóndigas (fangas) ${ }^{50}$.

Es probable que en las villas más modestas, como Aljezur, Alvor, Cacela o Alcoutim, el local de venta y descarga fuese el mismo ${ }^{51}$. La concentración de estas tareas en lugares predefinidos les permitía evaluar y controlar la cantidad y calidad del cereal que llegaba a la villa, la utilización de las medidas y pesos sancionados por el concejo, la calidad y el peso de los panes comercializados, los precios practicados, la legalidad de las transacciones, y por supuesto, el pago de los debidos impuestos ${ }^{52}$.

Al llegar el cereal, los poderes municipales vigilaban los precios del cereal, de los panes y de otros productos alimenticios $^{53}$, reservaban una parte para la venta directa al consumidor $^{54} \mathrm{y}$, con el apoyo regio, limitaban la actividad de los

${ }^{50}$ La documentación compulsada refiere la existencia de alhóndigas en Tavira (1352), Loulé (1375-1376), Lagos (1441), Faro (1441) e Silves (s. XV). BACL, Reservados, Série Azul, tomo 403. Collecção dos Documentos dos Cartorios do Algarve, Civis, e Ecclesiasticos, copiados por ordem da Academia Real das Sciencias em 1790, fl. 130v; Livro do Almoxarifado de Silves (século XV), prefácio H. B. Moreno; identificação e transcrição de M. J. da S. Leal; notas, observações e comentários de J. G. Domingues, Lisboa 1984, 21-22; A. IRIA, O Algarve nas cortes medievais portuguesas do século XV ..., 209; En 1352, Tavira solicita y consigue que Afonso IV mande ampliar las alhóndigas, debido a que el pan que venía de Castilla y de otros lugares ya no cabía en el edificio. BACL, Reservados, Série Azul, tomo 403. Colleç̧ão dos Documentos dos Cartorios do Algarve, Civis, e Ecclesiasticos, copiados por ordem da Academia Real das Sciencias em 1790, fl. 130v. En 1441, Lagos y Faro piden al monarca las rentas del salaio y del mordomado para reparar las alhóndigas y los azogues. Afonso $\mathrm{V}$ determina que, si las rentas fuesen recaudadas para la Corona, mandaría al contador correger los edificios. A. IRIA, O Algarve nas cortes medievais portuguesas do século XV ...209.

51 Tal es la realidad de otras villas portuguesas más modestas. I. GONÇALVES, Defesa do consumidor..., 101.

52 I. GonçALVES, Defesa do consumidor..., 100-102.

53 Actas de Vereação de Loulé. Séculos XIV-XV ..., 29-30 (Loulé, 1385).

54 En 1408, el concejo de Loulé reserva 1/3 del pescado para venta directa al consumidor, Actas de Vereação de Loulé. Séculos XIV-XV ..., 167. En 1498, en las cortes de Lisboa, los procuradores de Lagos piden al rei para confirmar una ordenanza de antigamente (...) per que se sempre usou por tanto tempo que a memoria dos homens non be em contrario, en la cual se determinaba que los mercaderes y regateras no pudiesen comprar 
revendedores, agentes intermediarios o, incluso, oficiales reales para evitar cualquier práctica especulativa en torno a los alimentos, siempre tan apetecible cuanto mayor sea la escasez de estos alimentos ${ }^{55}$. Todo para que el consumidor común pudiera adquirir el cereal o el pan por un precio considerado justo, tan bajo como sea posible. Sin embargo, cuando el cereal faltaba, era necesario ir más lejos. Las autoridades de las villas y ciudades portuarias del Algarve, tal como sus homólogas portuguesas ${ }^{56}$ y europeas $^{57}$, prohibían la salida de productos alimenticios ${ }^{58}$; impedían la exportación de algunas de sus mercancías más importantes, como el pescado 59 , a no ser que fuese a cambio de cereal; y enviaban emisarios y compradores donde había noticia

las mercancías que viniesen para la villa por mar o por tierra durante tres días. Durante ese período, los habitantes debían ser los únicos que comprasen lo que necesitaban para su aprovisionamiento. Al cabo de esos tres días, si fuese necesario, el concejo aún podía reservar $1 / 3$ de las mercancías para que los habitantes de la villa las siguiesen comprando directamente. Cortes Portuguesas: Reinado de D. Manuel I (Cortes de 1498). Organização e revisão geral J. J. A. DIAS. Lisboa, 2002, 419-420.

55 A los ejemplos de Loulé y Faro descritos en la nota 29 puede añadirse el caso de Lagos. En efecto, en el 1490, en las cortes de Évora, los procuradores de Lagos pidieron al rey que obligase a los pescadores a vender el pescado a los locales al mismo precio que se lo vendían a los castellanos, ya que les cobraban de 10 a 20 reales el milheiro/millar a los castellanos y entre 80 y 100 reales a los habitantes de la villa. J. M. da S. Marques, (dirs.), Descobrimentos Portugueses. Documentos para a sua História..., Vol. III, 364. En 1498, en las cortes de Lisboa, los procuradores de Lagos pidieron al rey que prohibiese a los rendeiros/arrendatario/renteros de las rendas regias, concretamente de las sisas y alfândegas/aduanas, adquirir mercancías para revender a los habitantes. Cortes Portuguesas: Reinado de D. Manuel I (Cortes de 1498)..., 419-420.

56 I. GONÇALVES, «A propósito do pão...», 57-60.

${ }^{57}$ H. R. Oliva Herrer, «Carestía y lucha política...», 899-937.

58 Actas de Vereação de Loulé. Séculos XIV-XV..., 223-224 (1487). En 1503, el gobierno municipal de Loulé prohibió la salida de trigo de la villa, PT-AMLLE-CMLLE-B-A-112, Actas de Vereação de 1503-1504, fl. [31v-32].

59 ANTT, Leitura Nova, Livro 2 do Guadiana, fl. 14-15 (Loulé, 1482); ANT'T, Chancelaria de D. Afonso V, liv. 15, fl. 146 (Faro, 1455); J. M. da S. MArQues, (dirs.), Descobrimentos Portugueses. Documentos para a sua História..., Vol. III, 364(Lagos, 1490), 636-638 (Lagos, 1482); Cortes Portuguesas: Reinado de D. Manuel I (Cortes de 1498)..., 422 (Lagos, 1498). En 1451, en las cortes de Santarém, los procuradores de Faro refieren que la villa llegaba a acoger pescadores extranjeros como vecinos, exentándolos de los encargos concejiles y dándoles casas sem dinheiros. Todo para que pescasen y, así, la villa pudiese contar con más pescado y usarlo como moneda de cambio por el pan que los almocreves traían. ANTT, Chancelaria de D. Afonso V, liv. 11, fl. 35.

«Alimentar la red urbana: las villas y ciudades portuarias del Algarve...» 
de que había pan, tanto en los mercados circundantes ${ }^{60}$, como en otros mercados nacionales, como en los casos de Beja, Serpa, Moura $^{61}$, Campo de Ourique ${ }^{62}$, Évora ${ }^{63}$ o Lisboa ${ }^{64}$, llegando incluso a territorios más alejados, como Castilla ${ }^{65}$, el Norte de África ${ }^{66} \mathrm{y}$, a partir del siglo XV, Bretaña ${ }^{67} \mathrm{y} \mathrm{Sicilia}^{68}$.

${ }^{60}$ Entre el 1374 y 1375, el concejo de Loulé compró cereal a Petrequim, mercader, para distribuír a varios almocreves. M. de F. BотÃo, A construção de uma..., 257. En el 1375, en un año de crisis cerealista, el concejo de Loulé mandó a Garcia da Costa procurar trigo en Silves, ya que Álvaro Gonçalves e Vasco Afonso, sacador, habían afirmado que el rey tenía cereal en la ciudad y podía dar una parte al concejo. Un año después, en el 1376, el concejo de Loulé mandó a João Durães y a Lourenço Eanes a Silves per raz̧ão dos navios do pão que portaram em Estômbar. Al mismo tiempo, el concejo de Loulé envió a Vasco Afonso, sacador, a comprar el trigo que llegaba a Lagos. Arquivo Municipal de Loulé, PT/AMLLE/AL/CMLLE/E/A/01/liv. 001, Livro de receita e despesa (1375-1376), fls. 18 e 26. En el 1403, cuando llega la noticia que una nau de pam arribó en Faro, el concejo de Loulé manda a Mestre Martim a negociar con el concejo de Faro la adquisición de parte del cereal, Actas de Vereação de Loulé. Séculos XIV-XV .., 113. En el 1462, cuando arribaron cuatro navíos vizcaínos en Faro, las autoridades concejiles compraron la mitad de la carga e informaron a Loulé que podía comprar la otra mitad, ya que Álvaro Afonso les había dicho que el concejo quería tomar parte en qualquer partido. La carga adquirida era probablemente cereal. BACL, Reservados, Série Azul, tomo 403, fl. 192v193. Durante los siglos XIV y XV, cuando faltaba pan, Albufeira adquiría el cereal y otros productos alimentarios en Loulé, Silves, Faro y Tavira ANTT, Chancelaria de D. João II, liv. 8, fl. 199-199v (1486).

61 ACMT, Reforma dos Tombos, tomo 1, fl. 90-90v (Tavira, 1374). ANT'T, Cortes, maço 2, $\mathrm{n}^{\circ} 14$, fls. 142-142v (Algarve, 1477).

62 En el año 1385, el concejo ordena a Diogo Rodrigues, notario, que pida un saco de pan a Beja y Campo de Ourique, Actas de Vereação de Loulé. Séculos XIV-XV..., 27.

63 ANTT, Leitura Nova, Livro 3 do Guadiana, fl. 29 (1468).

${ }^{64}$ En el 1424, los concejos de Loulé y Faro mandaron a Álvaro Afonso ir desde Faro a Lisboa por razãa de pão que acordaram que fizessem vir ao dito logo de Faro. Le correspondió al concejo de Loulé $1 / 3$ del cereal adquirido. Arquivo Municipal de Loulé, PT/AMLLE/AL/CMLLE/E/A/01/liv. 007, Livro de receita e despesa (1423-1425), fls. 32, 34. 35 e 40. En 1468, anticipándose a la llegada de trigo breton a Lisboa, Loulé pidió al rey 1000 moios del trigo. Afonso $\mathrm{V}$ tranquilizó a los gobernantes municipales prometiendo que les entregaría una parte del trigo cuando éste llegase, Actas de Vereação de Loulé. Séculos XIV-XV..., 204-205

65 ANTT, Cortes, maço 2, no 14, fls. 142 (1477).

${ }^{66}$ En el año 1414, Loulé y Tavira fueron autorizados por el monarca a ir a comerciar al Norte de África. El documento no lo deja claro, pero pensamos, tal como Maria de Fátima Botão, que era para adquirir cereal. BACL, Reservados, Série Azul, tomo 403. Collecção dos Documentos dos Cartorios do Algarve, Civis, e Ecclesiasticos, copiados por ordem da Academia Real das Sciencias em 1790, fl. 155v; M. de F. BОтÃO, A construção de uma..., p. 256. En el 1478, el rey autoriza a Tavira a vender sus novedades en las partes de África, 
No obstante, las principales villas y ciudades portuarias del Algarve parecen ser las únicas en Portugal que procuraron concertar estrategias para vencer estos problemas que afectaban a todas, pues solicitaron en conjunto al monarca que prohibiese la salida de cereales de la región ${ }^{69}$. Además, a partir del siglo $\mathrm{XV}$, negociaron cada vez más en conjunto la adquisición de cereal, tanto en el reino, como en el extranjero ${ }^{70}$, probablemente para aumentar su capacidad de negociación. En 1450, por ejemplo, Tavira y Faro nombraron una embaixada para ir a Lisboa, Oporto, Galicia, Vizcaya, Bayona y Bretaña, en la que estaba Miguel Fernandes, homem que sabe a terra toda e a linguagem. La embajada debía ser financiada también por Loulé y los restantes municipios algarvios. El documento no esclarece el objetivo de la embajada, pero sería posiblemente para convenir la compra de cereal a cambio de higos ${ }^{71}$.

Si existían obstáculos para el comercio, las villas y ciudades portuarias del Algarve conseguían habitualmente que el monarca concediera exenciones fiscales, en concreto en el pago

concretamente en Safim, durante dos años, a cambio de armas y cereal. ANTT, Leitura Nova, Livro 5 do Guadiana, fl. 113v. En el 1490, el rey autoriza a Lagos a comprar trigo en Mazagão y Casa do Cavaleiro (Casablanca). J. M. da S. MARQueS, (dirs.), Descobrimentos Portugueses. Documentos para a sua História..., Vol. III, 364. En el 1490, Tavira mandaba navíos al Norte de África para comprar cereales, ACMT, Reforma dos Tombos, tomo 1, fl. 106.

${ }^{67}$ En el 1451, las villas de Loulé y Faro mandaron un mensajero a la Bretaña en busca de pam, Actas de Vereação de Loulé. Séculos XIV-XV..., 210.

$68 \mathrm{~J}$. R. MagalHães, O Algarve económico..., 83-84.

${ }^{69}$ En 1393, D. João I, a petición de los concejos del Algarve, prohibió la salida de pan de la región. Incluso suprimió las licencias para exportar pan que ya había otorgado, pues el precio del pan había subido de 40 a 50 soldos el alqueire, a entre seis y ocho libras, Arquivo da Câmara Municipal de Tavira (en adelante ACMT), Reforma dos Tombos, tomo 1, fl. 124-124v.

${ }^{70}$ Consúltese sobre esta problemática las notas 60, 64, 66 e 67.

71 BACL, Reservados, Série Azul, tomo 403. Collecção dos Documentos dos Cartorios do Algarve, Civis, e Ecclesiasticos, copiados por ordem da Academia Real das Sciencias em 1790, fl. 158v-159. M. de F. ВОт̃̃o, A construção de uma..., 258.

«Alimentar la red urbana: las villas y ciudades portuarias del Algarve...» 
de la décima ${ }^{72}$, licencias de sacas; que levantara embargos sobre productos que podían ser intercambiados por cereal ${ }^{73}$; o incluso se permitía que este fuese adquirido en territorio enemigo. Entretanto, aunque los gobiernos municipales consiguieron autorización para comerciar con los adversarios musulmanes ${ }^{74}$, no les ocurrió lo mismo a los cristianos. En el 1477, durante la guerra luso-castellana (1375-1379) y en un momento de escasez de cereal, en las cortes de Montemor-o-Novo, los concejos del Algarve piden permiso al príncipe D. João para vender mercancías a los musulmanes en el Norte de África, respondiendo D. João que podía autorizarlos a comerciar durante dos años, después de consultar la bula papal otorgada a Afonso $\mathrm{V}$

72 Desde el reinado de Afonso III, los habitantes de los concejos algarvios estaban exentos del pago de la julgada y oitava del pan y del vino. G. M. da SiLVA, A Coroa, as vilas e o mar..., 521. En 1282, D. Dinis exentó a Faro del pago de la décima y de costumagens del cereal que viniese de fuera de Portugal. A. H. de O. MARQues, Introdução à história da agricultura..., 156. El Lavrador exentó a los habitantes de Tavira del pago de la décima en todos los productos que trajesen de Portugal para mantenimiento y reparación de sus casas. Más tarde, en 1338, Afonso IV extendió esa exención también a los productos que los tavirenses comprasen fuera del reino con esa finalidad, Chancelarias portuguesas: D. Afonso IV, org. A. H. de O. MARQues, vol. II: 1336-1340, Lisboa 1982, 232-233. Incluso en 1387, D. João I, a pedido de los concejos, concedió nuevamente el mismo privilegio a Tavira, pero lo extiende también a Loulé, Lagos, Silves, Faro, Castro Marim y, probablemente, a los restantes concejos algarvios. Chancelarias portuguesas: D. João I..., vol. II, tomo I: 1385-1392, 143-144 (Loulé, 1387), 144 (Lagos e Silves, 1387); Chancelarias portuguesas: D. João I..., vol. I, tomo III: 13841388, 227-228 (Tavira, 1387), 228 (Castro Marim, 1387). Las villas y ciudades portuarias del Algarve consiguieron que D. Duarte, D. Afonso V, D. João II y D. Manuel confirmasen ese privilegio. ANTT, Chancelaria de D. João II, liv. 8, fl. 202 (Castro Marim, 1486); ANTT, Chancelaria de D. Manuel, liv. 30, fl. 117v (Castro Marim, 1497); F. C. Beloto, «Pharonensia Monumenta Historica V - Documentos do século XV», Anais do Município de Faro. IX, 1979, 325-326 (1452). En 1452, una sentencia regia esclarece que el higo, la harina, el vino y el pan también estaban incluidos por este privilegio, a pesar de que el documento especificaba concretamente otros productos, como la madera, toneles, arcos y teja. F. C. BELOTO, «Pharonensia Monumenta Historica V...», 325-326 (1452).

${ }^{73}$ En 1460, en las cortes de Évora, Afonso V, a pedido de Loulé, vuelve a autorizar la venta de esparto y empreita a Castilla, pues los mercaderes castellanos traían como moneda de cambio muito trigo, farinha, centeio, favas, ervanças, armas e outras mercadorias de que a terra era abastada. ANTT, Leitura Nova, Livro 3 do Guadiana, fl. 104-104v.

${ }^{74}$ Consúltese las informaciones referidas en la nota 66. 
que permitía el comercio entre cristianos y musulmanes. No obstante, cuando los concejos algarvios solicitaron al príncipe que se les permitiese transportar y vender sus mercancías en Castilla, posiblemente a Andalucía, D. João determinó que por ora não há por bem de levarem suas mercadorias a Castela nem de lá tratarem $^{75}$.

Al mismo tiempo, siguiendo el ejemplo de otros centros urbanos $^{76}$, las villas y ciudades portuarias del Algarve querían garantizar que los mercaderes del cereal venían a sus mercados. Con este objetivo, los núcleos urbanos algarvios pusieron en marcha varias medidas suplementarias y de diferente naturaleza. Tavira expandió las alhóndigas (fangas) para acoger mejor el cereal que venía de Castilla (1352) ${ }^{77}$, entretanto Loulé se ofreció a pagar las sisas del pan que viniera de fuera $(1495)^{78}$. Faro tuvo una tienda para almacenar el cereal $(1424)^{79}$ y acogió a pescadores castellanos para aumentar su capacidad de pesca y, por consiguiente, tener más pescado para intercambiar por cereal ${ }^{80}$. Lagos consiguió el apoyo del monarca para que los mercaderes de Sicilia que cargasen pilas de atún para sus embarcaciones tuviesen prioridad, debido a la neçesjdade que ha nossa villa de Lagos tem de ser sempre proujda de pam de Fora pelo na dita vila e sua comarca nam aver em abastança $^{81}$. Un año después, en 1521, el concejo lacobrigense consiguió que este privilegio se extendiese a todas las embarcaciones que transportasen mercancías para Arzila o navíos extranjeros, siempre que viniesen cargados de cereal para vender en $\operatorname{Lagos}^{82}$.

\footnotetext{
75 ANTT, Cortes, maço 2, no 14, fls. 140-140v, 142-142v (1477)

76 I. GONÇALVES, «A propósito do pão...», 59-60.

77 BACL, Reservados, Série Azul, tomo 403. Collecção dos Documentos dos Cartorios do Algarve, Civis, e Ecclesiasticos, copiados por ordem da Academia Real das Sciencias em 1790, fl. 130v.

78 Actas de Vereação de Loulé. Século XV. Separata da Al'-ulyã: Revista do Arquivo Histórico Municipal de Loulé. Loulé 2004, 189.

79 Arquivo Municipal de Loulé, PT/AMLLE/AL/CMLLE/E/A/01/liv. 007, Livro de receita e despesa (1423-1425), fls. 35 .

80 ANTT, Chancelaria de D. Afonso V, liv. 11, fl. 35. Véase nota 59.

81 J. R. MagalHães, $O$ Algarve económico..., 83;

82 ANTT, Chancelaria de D. Manuel, liv. 37, fl. 88v.
}

«Alimentar la red urbana: las villas y ciudades portuarias del Algarve...» 
Sin embargo, todos los concejos algarvios parecem ser unánimes en intentar obtener del rey cartas de seguridad para los mercaderes que les trajeran cereal y leguminosas ${ }^{83}$ y, principalmente, exenciones fiscales, concretamente exención del pago de la décima y, en algunos casos, de la mitad de las sisas de trigo y otros cereales panificables, harina, legumbres, bizcocho y castañas importadas $^{84}$. Según la documentación conocida, la Corona otorgó a los concejos algarvios, por lo menos, veintiocho cartas a autorizar exenciones fiscales, siendo la mayoría concedidas durante la segunda mitad del siglo XV $(83 \%)^{85}$. Faro (cinco), Lagos (seis), Silves (seis) e Tavira (siete) fueron los núcleos urbanos que mais exenciones recibieron. Los concejos algarvios acostumbraban solicitar las exenciones fiscales durante y, principalmente, en los primeros meses después de la sementera

83 ANTT, Chancelaria de D. Afonso V, liv. 15, fl. 144v-145 (Loulé, 1455), liv. 33, fl. 219 (Tavira, 1473), liv. 36, fl. 169 (Faro, Algarve, 1459), liv. 36, fl. 172 (Tavira, Algarve, 1459); ANT'T, Leitura Nova, Livro 3 do Guadiana, fl. 84v (Silves, Algarve, 1459), Livro 5 do Guadiana, fl. 113v (Tavira, 1478); A. IRIA, O Algarve nas cortes medievais portuguesas do século XV ..., 224 (Faro, 1444), 232-232 (Tavira, 1447); Actas de Vereação de Loulé. Séculos XIV-XV .., 204 (Algarve, 1468)

84 Consulte los documentos citados en la nota 85. En 1498 e 1514, en cortes, Lagos solicitó la exención del pago de la décima de todo el pan y legumbres que viniese de fuera del reino durante un período de 10 años, pero no sabemos si el monarca respondió favorablemente al pedido concejil. ANTT, Gaveta 20, maço 2, nº 65; Cortes Portuguesas: Reinado de D. Manuel I (Cortes de 1498)..., 419.

85 ANTT, Chancelaria de D. Afonso V, liv. 2, fl. 70v (Faro, 1441), liv. 5, fl. 22 (Faro, 1446), liv. 10, fl. 32 (Faro, 1454), 45v (Silves, 1454), 46 (Lagos, 1454), liv. 11, fl. 124 (Tavira, 1451), liv. 12, fl. 17v (Faro, 1452), 29v (Lagos, 1452), 129 (Tavira, 1452), liv. 15, fl. 103 (Loulé, 1454), liv. 22, fl. 132 (Lagos, 1471), 132v (Lagos, 1471), liv. 29, fl. 30v (Loulé e Silves, 1471), liv. 36, fl. 114 (Lagos, 1459), 169 (Algarve, 1459), 172 (Tavira, 1459), liv. 37, fl. 14v (Loulé, 1451); ANTT, Chancelaria de D. João II, liv. 9, fl. 39 (Silves, 1491), liv. 13, fl. 83 (Tavira, 1489), 94 (Lagos, 1488); ANTT, Chancelaria de D. Manuel, liv. 8, fl. 19 (Tavira, 1511); ANTT, Leitura Nova, Livro 3 do Guadiana, fl. 28v (Tavira, 1468), 84v (Silves, 1459); A. IRIA, O Algarve e a Ilha da Madeira no século XV (Documentos Inéditos). Lisboa 1974, 114-115 (Silves, 1452); A. IRIA, O Algarve nas cortes medievais portuguesas do século XV..., 188 (Silves, 1413); Cortes Portuguesas: Reinado de D. Manuel I (Cortes de 1498), 405 (Faro, 1495). 
(Octubre - Diciembre), sobretodo en Enero y Febrero, pero también en el transcurso de la cosecha (Junio - Septiembre) ${ }^{86}$.

Las exenciones fiscales solían concederse durante uno o, principalmente, dos años, pero también existen casos que podían llegar a tres o cuatro. De esta forma, en 1488, Lagos se benefició de la exención del pago de la décima sobre el pan importado durante diez años, asimismo, en 1514, Tavira también estuvo exenta de este pago hasta el fin de la vida del monarca, en $1521^{87}$. De hecho, las villas y ciudades del Algarve parecen ser - en su conjunto - los núcleos que más se han beneficiado de estos privilegios, siendo únicamente superados por Lisboa ${ }^{88}$.

Sin embargo, cuando los casos eran realmente graves, como las hambrunas de la década de los 80 del siglo XIV, de 1455 y 1468, urgía tomar medidas drásticas. Desde luego, y una vez más siguiendo una práctica común ${ }^{89}$, los municipios algarvíos fijaban los precios, imponían límites máximos ${ }^{90}$ y decretaban racionamientos $^{91}$. Si ni siquiera así la tierra era abastecida, cuando había una comunidad musulmana, las autoridades municipales toman o pescado, o marisco e a caça de los sarracenos. La comunidad musulmana era forzada a vender sus alimentos en lugares y horas

\footnotetext{
${ }^{86} \mathrm{~J}$. R. Magalhães, O Algarve económico..., 56-57. Consulte los documentos citados en la nota 85 .

87 Consulte los documentos citados en la nota 85 .

88 A. H. de O. MARQues, Introdução à história da agricultura..., 134, 135, 157, 257-281. Consulte los documentos citados en la nota 85.

${ }^{89}$ I. GONÇALVES, «A propósito do pão...», 60.

${ }^{90}$ En 1385, año de hambre general, las autoridades de Loulé estipulan el precio del boom triigo en los 25 sueldos o alqueire/fanega y el outro mais somenos se ponha mais baixo e meos, Actas de Vereação de Loulé. Séculos XIV-XV ..., 29-30. En Évora, el precio del pan había sido fijado en 20 sueldos o alqueire, pero el documento no esclarece claramente si ese valor también fue atribuido al pan de menor calidad en Loulé, como afirma Maria de Fátima Botã, Actas de Vereação de Loulé. Séculos XIV-XV ..., 29-30; M. de F. Вот̃̃o, A construção de uma..., 257.

91 Actas de Vereação de Loulé. Séculos XIV-XV ..., 29-30 (Loulé, 1385); ANTT, Chancelaria de D. Afonso V, liv. 15, fl. 144v (Loulé, 1455).
}

«Alimentar la red urbana: las villas y ciudades portuarias del Algarve...» 
específicas, así como a trabajar como jornaleros por vencimientos reducidos ${ }^{92}$.

De igual modo, los municipios algarvios, principalmente los ubicados en la costa, tomaban a la fuerza embarcaciones que traían cereal, aunque fuera a otros municipios de la región ${ }^{93}$. En 1455, en las cortes, el procurador de Loulé afirmó que la villa, tal vez junto con Faro, había negociado y ofrecido ventajas a extranjeros y mercaderes de Castilla para traer cereal. Sin embargo, tan pronto como los barcos aparecían a lo largo de la costa, los habitantes dela villa de Tavira salían em navios armados a eles e tomam o dito pão e o levam, por causa da carestia e mingua que havia. Loulé afirmaba que la situación era recurrente y el corregidor deu pouco por elo e leixon passar tudo com pouco castigo. Ante eso, Afonso $\mathrm{V}$ prohibió el ataque a barcos que traían trigo contratado. En realidad, al contrario de lo que ocurre para otras ciudades portuarias $^{94}$, la legislación parece no sancionar aquí los ataques a embarcaciones cuando se trataba del abastecimiento del núcleo urbano.

Por fin, en 1468, el monarca fue obligado a enviar a João de Elvas, su procurador, al Algarve para socorrer aas voltas, bandos e arroydos que com pouco temor de Deus e nosso se fazem e cometem no nosso Reyno do Algarve, posiblemente debido a la crisis cerealista que afectaba a toda la región. Afonso $\mathrm{V}$ dotaba a João de Elvas con jurisdicción civil y crimen, así como el rey tenía y como dela husaria ho corregedor da nosa Corte com toda nossa Rolaçam se pressene fosse. Así, João de Elvas podía condenar a los culpables al degredo, al

\footnotetext{
92 História florestal, aquícola e cinegética. Colectânea de documentos existentes no Arquivo Nacional da Torre do Tombo. Chancelarias reais. Ed. C. B. das NeVES, Vol. IV. Lisboa 1982, 165-168 (Tavira, Loulé, Faro e Loulé, 1383).

93 ANTT, Chancelaria de D. Afonso V, liv. 15, fl. 144v-145 (Loulé, 1455).

94 Por ejemplo, el caso de Barcelona: A. RIERA I MELIS, «Tener siempre bien aprovisionada la población: los cereales y el pan en las ciudades catalanas durante la Baja Edad Media», en B. Arízaga Bolumburu y J. Solórzano Telechea (coord.), Alimentar la ciudad en la Edad Media. Logroño 2009, 39.
} 
desmembramiento o, incluso, a la muerte ${ }^{95}$. Al mismo tiempo, Afonso $\mathrm{V}$ determinaba que los caballeros que participasen en los disturbios fueran condenados a dos años de servicio en el coto del Sabugal (comarca de Beira) y los peones durante un año para Cabo Verde (África) ${ }^{96}$.

\section{Resultados y consecuencias: algunas reflexiones}

Desafortunadamente, en el Algarve, como sucede con otras regiones portuguesas y europeas, la documentación reunida no nos permite conocer claramente los resultados prácticos de las políticas utilizadas en la lucha contra las crisis alimentarias y las hambrunas, lo que dificulta la percepción del impacto efectivo demográfico y socioeconómico de las crisis alimentarias y hambres, o hasta que punto fueron un argumento manejado ante los monarcas para adquirir privilegios y regalías ${ }^{97}$. ¿Fueron las medidas de los gobiernos municipales suficientes para combatir las crisis alimentarias y el hambre? ¿su aplicación perjudicó seriamente las finanzas municipales? ¿la evolución de los precios del cereal provocó el empobrecimiento y endeudamiento de las capas sociales más bajas, como ocurre con el campesinado andaluz ${ }^{98}$ ? ¿consiguieron los estratos sociales más modestos de la población sustituir el cereal por otro recurso? Aunque de forma

\footnotetext{
95 Actas de Vereação de Loulé. Séculos XIV-XV ..., 215-216.

96 Actas de Vereação de Loulé. Séculos XIV-XV ..., 217-218.

97 Tales dificultades son extensibles a otras regiones del Portugal medieval, donde la documentación raramente proporciona datos seriales que nos permitan responder a estas cuestiones. El panorama es distinto para Castilla y, de modo particular, para Andalucía. Léase, sobre este asunto, H. R. Oliva Herrer, "Carestía y lucha política...», 899-937, y la bibliografía ahí presentada, bien como los trabajos que hemos ido citando de Pere Benito i Monclús, Hipólito Rafael Oliva Herrer y también M. A. LADERo Quesada y M. GONZÁLEZ JimÉNEZ, Dieżmo eclesiástico y producción de cereales en reino de Sevilla: 1408-1503. Sevilha 1979.

98 Léase sobre este caso: M. Borrero FERnÁndez, Propiedad campesina y crisis agrarias: Andalucía a principios del siglo XVI, en H. R. Oliva Herrer y P. Benito I MONCLÚS (coord.), Crisis de subsistencia y crisis agrarias en la Edad Media. Sevilha 2007, 303-330; J. L. VilLALONGA SERRANO, «Crisis y endeudamiento en la campiña sevillana a finales de la Edad Media», en H. R. Oliva Herrer y P. Benito i Monclús (coord.), Crisis de subsistencia y crisis agrarias en la Edad Media, Sevilla 2007, 331-357.
}

«Alimentar la red urbana: las villas y ciudades portuarias del Algarve...» 
tardía, la Corografia de Frei João de São José (1577) revela que los grupos sociales más desfavorecidos recurrían a los higos con éxito para colmar la escasez de cereal, lo que sería posiblemente una práctica más antigua:

"É o figo bom mantimento, em especial pera os do Algarve, que o têm já em costume, e serve muitas vezes em lugar de pão à gente dos montes e aos pobres e também de cevada às bestas, de farelos aos porcos e ainda aos cães e gatos, porque, enquanto ele dura, todos geralmente participam dele. E a todos sustenta e, por isso, chamam os Mouros a este tempo alacil, que quer dizer em sua língua mesa de Deus, que a todos farta. ${ }^{99}$

Cuando eran convocadas a cortes por el monarca, las villas y ciudades portuarias del Algarve se quejaban de que tanto la falta de pan y las hambrunas - aisladas o asociadas a otros problemas como las guerras, las pestes o las catástrofes naturalesacaban por provocar despoblamiento ${ }^{100}$, la venta anticipada de la fruta para adquirir cereal ${ }^{101}$, la especulación en torno a los productos alimenticios ${ }^{102}$, la subida de los precios de los cereales y la fuga de habitantes a tierras donde el trigo abundaba ${ }^{103}$. A lo largo de toda la cronología en análisis, la restante documentación reunida permite corroborar la existencia de prácticas especulativas $^{104}$ y la subida de los precios de los cereales. En efecto, el valor de los cereales en las villas y ciudades algarvias fue bastante superior al registrado en otros núcleos urbanos portugueses, como Coímbra, Braga, Ceuta o Alcobaça ${ }^{105}$.

\footnotetext{
99 J. R. de Magalhães y M. V. Guerrero (eds.), Duas Descrições do Algarve do Século XVI, Lisboa 1983, 114 (negrito colocado por nosotros).

100 J. M. da S. MARQues (dirs.), Descobrimentos Portugueses..., Vol. III, 363 (Lagos, 1490)

101 A. IRIA, O Algarve nas cortes medievais portuguesas do século XV ..., 204 (Faro, 1440)

102 ANTT, Chancelaria de D. Afonso V, liv. 15, 144v (Loulé, 1455)

103 BACL, Reservados, Série Azul, tomo 403, fl. 129, 132 (Tavira, 1352)

104 Actas de Vereação de Loulé. Séculos XIV-XV ..., 29-30.

105 S. C. Ferreira, Preços, Salários e Niveis de Vida..., 181.
} 
En suma, las estrategias que las villas y ciudades portuarias algarvias trazaron y su éxito - como, por ejemplo, la capacidad de adquirir normalmente el cereal en el extranjero y conseguir importantes beneficios fiscales regios, como la exención del pago de la décima y de la sisa -, asociadas a la escasez de referencias a revueltas urbanas, puede posiblemente significar que las villas y ciudades respondieron con alguna eficacia al problema del abastecimiento, obligando a revisar el peso efectivo de los problemas denunciados en Cortes. Es probable que los núcleos urbanos más importantes de la región Lagos, Portimão, Silves, Albufeira, Loulé, Faro, Tavira e Castro Marim - hayan conseguido contornar mejor estas adversidades que los más modestos, como Sagres, Aljezur, Alvor, Cacela, y Alcoutim, beneficiándose de un acceso propio y más fácil a los mercados abastecedores.

\section{Consideraciones finales}

En suma, en los siglos XIV y XV, las villas y ciudades portuarias del Algarve registraron varias crisis alimentarias y hambrunas, tanto debido a factores endógenos, como exógenos. La Corona y los gobiernos municipales desarrollaron algunas medidas agrícolas tendientes al incremento de la producción de cereal, pero, debido a la pobreza de los suelos, parecen apostar principalmente a las medidas comerciales. Así, las villas y las ciudades portuarias del Algarve, como otras, parecen recibir y depender del cereal que llega por el mar. Sin embargo, conocer el grado de eficacia de las políticas seguidas por los gobiernos municipales contra las crisis alimentarias y las hambrunas sigue siendo difícil de medir, aunque algunos indicios apuntan al éxito de las estrategias adoptadas, que se repiten a menudo. El caso del Algarve nos lleva a plantear algunas cuestiones que consideramos importantes: ¿Los núcleos urbanos portuarios logran responder más fácilmente a las hambrunas de que los restantes debido al abastecimiento marítimo? ¿De qué forma las crisis de cereales del Algarve se interrelacionan con las crisis de cereales en Andalucía? 
¿De qué forma las crisis de cereales perjudicaron o estimularon el comercio de otros productos, como el higo o el pescado, a fin de garantizar moneda de cambio para negociar el cereal?

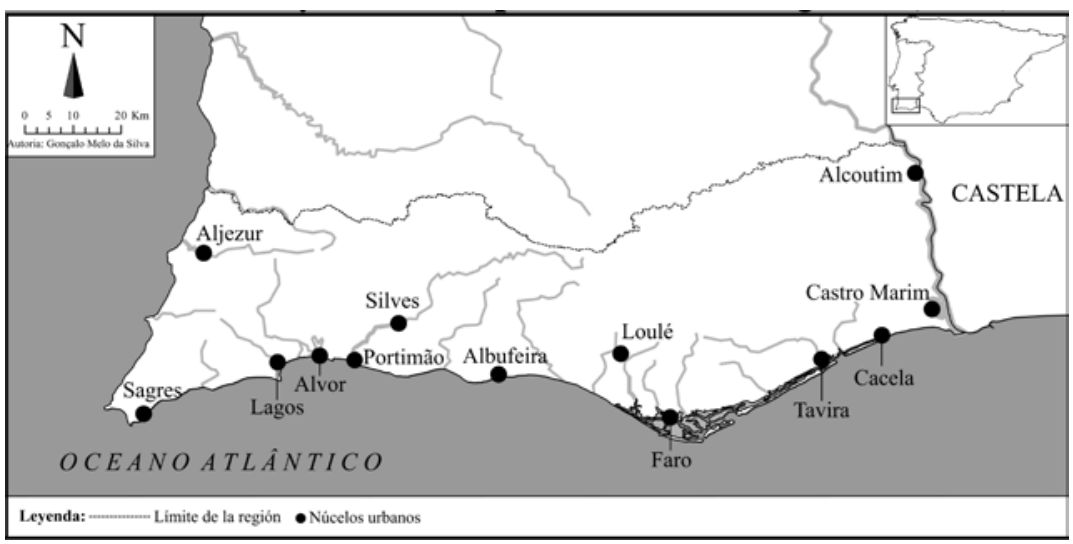

Figura 1. Las villas y cindades portuarias del Algarve (1521) 


\begin{tabular}{|c|c|c|c|c|c|}
\hline Data & $\mathrm{Pt}$ & $\mathrm{Al}$ & $\begin{array}{l}\text { Núcleos } \\
\text { Urbanos del } \\
\text { Algarve }\end{array}$ & An & Fuente \\
\hline 1302 & $\mathrm{X}$ & & & & $\begin{array}{l}\text { A. H. de O. MARQUES, Introdução..., 39; M. J. P. } \\
\text { F. TAVARES, Os sinais..., } 499\end{array}$ \\
\hline 1303 & $\mathrm{X}$ & & & & $\begin{array}{l}\text { A. H. de O. MARQUES, Introdução..., 39; M. J. P. } \\
\text { F. TAVARES, Os sinais..., } 499\end{array}$ \\
\hline 1304 & $\mathrm{X}$ & & & & $\begin{array}{l}\text { A. H. de O. MARQUES, Introdução..., 39; M. J. P. } \\
\text { F. TAVARES, Os sinais..., } 499\end{array}$ \\
\hline 1331 & $\mathrm{X}$ & & & & $\begin{array}{l}\text { A. H. de O. MARQUES, Introdução..., 41; M. J. P. } \\
\text { F. TAVARES, Os sinais...,501 }\end{array}$ \\
\hline 1333 & $\mathrm{X}$ & & & & $\begin{array}{l}\text { M. J. P. F. TAVARES, Os sinais...501; S. C. } \\
\text { FERREIRA, Precos ..., 85-86 }\end{array}$ \\
\hline 1334 & $\mathrm{X}$ & & & & S. C. FERREIRA, Preços..., $86-87$ \\
\hline 1338 & & & Tavira & & Chancelarias portuguesas: D. Afonso IV, vol. II, 232-233 \\
\hline 1348 & $\mathrm{X}$ & & & & M. J. P. F. TAVARES, Os sinais..., 502 \\
\hline 1352 & & & Tavira & & BACL, Reservados, Série Azul, 403, fl. 129, 132 \\
\hline 1354 & $\mathrm{X}$ & & & & $\begin{array}{l}\text { A. H. de O. MARQUES, Introdução..., 257; M. J. P. } \\
\text { F. TAVARES, Os sinais..., } 502\end{array}$ \\
\hline 1355 & $\mathrm{X}$ & & & & $\begin{array}{l}\text { A. H. de O. MARQUES, Introdução..., 41, 258; M. } \\
\text { J. P. F. TAVARES, Os sinais..., 502; S. C. } \\
\text { FERREIRA, Preços ... 90-91 }\end{array}$ \\
\hline 1356 & $\mathrm{X}$ & & & & $\begin{array}{l}\text { A. H. de O. MARQUES, Introdução...,41, 258; M. J. } \\
\text { P. F. TAVARES, Os sinais...,503; S. C. FERREIRA, } \\
\text { Preços, Salários e Níveis de Vida..., 90-91 }\end{array}$ \\
\hline 1364 & $\mathrm{X}$ & & & & $\begin{array}{l}\text { A. H. de O. MARQUES, Introdução..., 42; M. J. P. } \\
\text { F. TAVARES, Os sinais..., } 503\end{array}$ \\
\hline 1365 & $\mathrm{X}$ & & & & $\begin{array}{l}\text { A. H. de O. MARQUES, Introdução... ,42; M. J. P. } \\
\text { F. TAVARES, Os sinais..., } 503\end{array}$ \\
\hline 1366 & $\mathrm{X}$ & & & & $\begin{array}{l}\text { A. H. de O. MARQUES, Introdução..., 42, 258; M. J. } \\
\text { P. F. TAVARES, Os sinais... } 503\end{array}$ \\
\hline 1371 & $\mathrm{X}$ & & & & $\begin{array}{l}\text { A. H. de O. MARQUES, Introdução..., 42-43, 259; } \\
\text { M. J. P. F. TAVARES, Os sinais..., } 503\end{array}$ \\
\hline 1372 & $\mathrm{X}$ & & Loulé & & $\begin{array}{l}\text { A. H. de O. MARQUES, Introdução...,43, 259; M. J. } \\
\text { P. F. TAVARES, Os sinais...,503; ANTT, Chancelaria } \\
\text { de D. João II, liv. 8, fl. 180v (Loulé, 1486) }\end{array}$ \\
\hline 1374 & $\mathrm{X}$ & & Tavira & & $\begin{array}{l}\text { ACMT, Reforma dos Tombos, t. 1, fl. 90-90v (Tavira);A. } \\
\text { H. de O. MARQUES, Introdução..., 43, 259; M. J. P. } \\
\text { F. TAVARES, Os sinais..., } 504\end{array}$ \\
\hline 1375 & $\mathrm{X}$ & & Silves, Loulé & & $\begin{array}{l}\text { IRIA, Alberto, O Algarve...,94-95; Descobrimentos } \\
\text { Portugueses, II, 1, 312-313; A. H. de O. MARQUES, } \\
\text { Introdução...,43, 260; M. J. P. F. TAVARES, Os } \\
\text { sinais..., } 504\end{array}$ \\
\hline 1376 & $\mathrm{X}$ & & $\begin{array}{l}\text { Lagos, } \\
\text { Albufeira, } \\
\text { Faro, Loulé, } \\
\text { Tavira, Silves }\end{array}$ & & $\begin{array}{l}\text { A. H. de O. MARQUES, Introdução..., 259; ANTT, } \\
\text { Chancelaria de D. João II, liv. 8, fl. 199-199v }\end{array}$ \\
\hline 1380 & $\mathrm{X}$ & & & & S. C. FERREIRA, Preços...99-101 \\
\hline 1381 & $\mathrm{X}$ & & & & S. C. FERREIRA, Preços...,99-101 \\
\hline 1384 & $\mathrm{X}$ & & & & M. J. P. F. TAVARES, Os sinais...,504 \\
\hline
\end{tabular}

«Alimentar la red urbana: las villas y ciudades portuarias del Algarve...» 


\begin{tabular}{|c|c|c|c|c|c|}
\hline 1385 & $\mathrm{X}$ & & Loulé & & $\begin{array}{l}\text { Actas de Vereação de Loulé. Séculos XIV-XV, 29; A. H. } \\
\text { de O. MARQUES, Introdução...43; M. J. P. F. } \\
\text { TAVARES, Os sinais...,504 }\end{array}$ \\
\hline 1386 & $\mathrm{X}$ & & & & $\begin{array}{l}\text { A. H. de O. MARQUES, Introdução...,43, } \\
\text { M. J. P. F. TAVARES, Os sinais..., } 504\end{array}$ \\
\hline 1387 & $\mathrm{X}$ & & & & $\begin{array}{l}\text { A. H. de O. MARQUES, Introdução...43, 262;M. J. } \\
\text { P. F. TAVARES, Os sinais...,504 }\end{array}$ \\
\hline 1391 & $\mathrm{X}$ & & & & A. H. de O. MARQUES, Introdução...,43, 262 \\
\hline 1392 & $\mathrm{X}$ & & & & A. H. de O. MARQUES, Introdução...,3, 262 \\
\hline 1393 & & $\mathrm{X}$ & & & ACMT, Reforma dos Tombos, 1, fl. $124-124 \mathrm{v}$ \\
\hline 1394 & $\mathrm{X}$ & & & & $\begin{array}{l}\text { A. H. de O. MARQUES, Introdução...43, 262-263; } \\
\text { M. J. P. F. TAVARES, Os sinais...,504 }\end{array}$ \\
\hline 1396 & & & Loulé & & M. J. P. F. TAVARES, Os sinais..., 505 \\
\hline 1397 & & & & & A. H. de O. MARQUES, Introdução...,262-263 \\
\hline $1398 ?$ & & $\mathrm{X}$ & & & M. J. P. F. TAVARES, Os sinais..., 505 \\
\hline 1398 & $\mathrm{X}$ & & & & $\begin{array}{l}\text { A. H. de O. MARQUES, Introdução...,262-263; S. C. } \\
\text { FERREIRA, Preços...,104 }\end{array}$ \\
\hline 1399 & $\mathrm{X}$ & & & & A. H. de O. MARQUES, Introdução..., 262-263 \\
\hline 1400 & $\mathrm{X}$ & & & & A. H. de O. MARQUES, Introdução..., 262-264 \\
\hline 1402 & $\mathrm{X}$ & & & & S. C. FERREIRA, Preços...,105-106 \\
\hline 1403 & $\mathrm{X}$ & & & & $\begin{array}{l}\text { A. H. de O. MARQUES, Introdução...,264; S. C. } \\
\text { FERREIRA, Preços...,105-106 }\end{array}$ \\
\hline 1408 & & & & $\mathrm{X}$ & $\begin{array}{l}\text { M. A. LADERO QUESADA y M. GONZÁLEZ } \\
\text { JIMÉNEZ, Diezmo..., pp. 52, } 117 .\end{array}$ \\
\hline 1410 & $\mathrm{X}$ & & & & $\begin{array}{l}\text { A. H. de O. MARQUES, Introdução...,43; M. J. P. F. } \\
\text { TAVARES, Os sinais..., } 505 .\end{array}$ \\
\hline 1411 & $\mathrm{X}$ & & & & $\begin{array}{l}\text { A. H. de O. MARQUES, Introdução..., 43; M. J. P. } \\
\text { F. TAVARES, Os sinais...,505 }\end{array}$ \\
\hline 1412 & $\mathrm{X}$ & & & & $\begin{array}{l}\text { A. H. de O. MARQUES, Introdução..., 43, 265-267; } \\
\text { M. J. P. F. TAVARES, Os sinais..., 505; S. C. } \\
\text { FERREIRA, Preços..., 106-108 }\end{array}$ \\
\hline 1413 & $\mathrm{X}$ & & Silves & $\mathrm{X}$ & $\begin{array}{l}\text { A. IRIA, O Algarve..., 188; A. H. de O. MARQUES, } \\
\text { Introdução..., 43, 265-267; M. J. P. F. TAVARES, Os } \\
\text { sinais..., 505; S. C. FERREIRA, Preços...,107-108; M. } \\
\text { A. LADERO QUESADA y M. GONZÁLEZ } \\
\text { JIMÉNEZ, Diezmo..., 38-39, 52, } 117 .\end{array}$ \\
\hline 1414 & $\mathrm{X}$ & & Tavira & $\mathrm{X}$ & $\begin{array}{l}\text { A. H. de O. MARQUES, Introdução..., 43, 265-267; } \\
\text { M. J. P. F. TAVARES, Os sinais..., 505; S. C. } \\
\text { FERREIRA, Preços...,107-108; M. A. LADERO } \\
\text { QUESADA y M. GONZÁLEZ JIMÉNEZ, } \\
\text { Diezmo..., 38-39, 52, } 117 .\end{array}$ \\
\hline 1418 & $\mathrm{X}$ & & & & $\begin{array}{l}\text { A. H. de O. MARQUES, Introdução..., 267; M. J. P. } \\
\text { F. TAVARES, Os sinais..., } 505\end{array}$ \\
\hline 1422 & $\mathrm{X}$ & & & $\mathrm{X}$ & $\begin{array}{l}\text { A. H. de O. MARQUES, Introdução..., 44, 267-268; } \\
\text { M. J. P. F. TAVARES, Os sinais..., 506; S. C. } \\
\text { FERREIRA, Preços..., 111; M. A. LADERO } \\
\text { QUESADA y M. GONZÁLEZ JIMÉNEZ, } \\
\text { Diezmo..., } 117 .\end{array}$ \\
\hline 1423 & $\mathrm{X}$ & & & $\mathrm{X}$ & $\begin{array}{l}\text { A. H. de O. MARQUES, Introdução..., 44, 267-268; } \\
\text { M. J. P. F. TAVARES, Os sinais..., 506; S. C. } \\
\text { FERREIRA, Preços..., 111; M. A. LADERO }\end{array}$ \\
\hline
\end{tabular}




\begin{tabular}{|c|c|c|c|c|}
\hline & & & & $\begin{array}{l}\text { QUESADA y M. GONZÁLEZ JIMÉNEZ, } \\
\text { Diezmo..., 52, } 117 .\end{array}$ \\
\hline 1424 & $\mathrm{X}$ & & & $\begin{array}{l}\text { A. H. de O. MARQUES, Introdução...,44, 267-268; } \\
\text { M. J. P. F. TAVARES, Os sinais..., 506; S. C. } \\
\text { FERREIRA, Preços..., 111-112 }\end{array}$ \\
\hline 1425 & $\mathrm{X}$ & & & $\begin{array}{l}\text { A. H. de O. MARQUES, Introdução..., 44, 267-268; } \\
\text { M. J. P. F. TAVARES, Os sinais...,506; S. C. } \\
\text { FERREIRA, Preços..., 111-112 }\end{array}$ \\
\hline 1426 & $\mathrm{X}$ & & & $\begin{array}{l}\text { A. H. de O. MARQUES, Introdução..., 44, 267-268; } \\
\text { M. J. P. F. TAVARES, Os sinais...,506; S. C. } \\
\text { FERREIRA, Preços..., 111-112 }\end{array}$ \\
\hline 1427 & $\mathrm{X}$ & & & $\begin{array}{l}\text { A. H. de O. MARQUES, Introdução..., 44, 267-268; } \\
\text { M. J. P. F. TAVARES, Os sinais..., 506; S. C. } \\
\text { FERREIRA, Preços..., 111-112 }\end{array}$ \\
\hline 1435 & & & $\mathrm{X}$ & $\begin{array}{l}\text { M. A. LADERO QUESADA y, M. GONZÁLEZ } \\
\text { IIMÉNEZ, Diezmo..., 39-40, 52, } 117 .\end{array}$ \\
\hline 1436 & & & $\mathrm{X}$ & $\begin{array}{l}\text { M. A. LADERO QUESADA y M. GONZÁLEZ } \\
\text { JIMÉNEZ, Diezmo..., 39-40, 52, } 117 \text {. }\end{array}$ \\
\hline 1437 & $\mathrm{X}$ & & & $\begin{array}{l}\text { A. H. de O. MARQUES, Introdução...,44, 268-272; } \\
\text { M. J. P. F. TAVARES, Os sinais..., 506; S. C. } \\
\text { FERREIRA, Preços...,116-120 }\end{array}$ \\
\hline 1438 & $\mathrm{X}$ & & & $\begin{array}{l}\text { A. H. de O. MARQUES, Introdução..., 44, 268-272; } \\
\text { M. J. P. F. TAVARES, Os sinais..., 506; S. C. } \\
\text { FERREIRA, Preços..., 116-120 }\end{array}$ \\
\hline 1439 & $\mathrm{X}$ & & & $\begin{array}{l}\text { A. H. de O. MARQUES, Introdução...,44, 268-272; } \\
\text { M. J. P. F. TAVARES, Os sinais..., 506; S. C. } \\
\text { FERREIRA, Preços..., 116-120 }\end{array}$ \\
\hline 1440 & $\mathrm{X}$ & Silves & & $\begin{array}{l}\text { A. IRIA, O Algarve..., 201;A. H. de O. MARQUES, } \\
\text { Introdução...44, 268-272; M. J. P. F. TAVARES, Os } \\
\text { sinais.., 506; S. C. FERREIRA, Preços..., 116-120 }\end{array}$ \\
\hline 1441 & $\mathrm{X}$ & Faro & $\mathrm{X}$ & $\begin{array}{l}\text { ANTT, Chancelaria de D. Afonso V, liv. 2, fl. 70v, } \\
\text { A. H. de O. MARQUES, Introdução..., 44, 268-272; } \\
\text { M. J. P. F. TAVARES, Os sinais..., 506; S. C. } \\
\text { FRREIRA, Preços..., 116-120; M. A. LADERO } \\
\text { QUESADA y M. GONZÁLEZ JIMÉNEZ, } \\
\text { Diezmo..., 40, } 117 .\end{array}$ \\
\hline 1445 & $\mathrm{X}$ & & & A. H. de O. MARQUES, Introdução...,272 \\
\hline 1446 & $\mathrm{X}$ & Faro & & $\begin{array}{l}\text { ANTT, Chancelaria de D. Afonso V, liv. 5, fl. 22; A. H. } \\
\text { de O. MARQUES, Introdução..., 272; M. J. P. F. } \\
\text { TAVARES, Os sinais..., } 507\end{array}$ \\
\hline 1448 & & & $\mathrm{X}$ & $\begin{array}{l}\text { M. A. LADERO QUESADA y M. GONZÁLEZ } \\
\text { JIMÉNEZ, Diezmo... 40, } 117 .\end{array}$ \\
\hline 1449 & $\mathrm{X}$ & & $\mathrm{X}$ & $\begin{array}{l}\text { S. C. FERREIRA, Preços..., 122; M. A. LADERO } \\
\text { QUESADA, M. GONZÁLEZ JIMÉNEZ, } \\
\text { Diezmo..., 40, } 117 .\end{array}$ \\
\hline 1452 & $\mathrm{X}$ & Loulé & & $\begin{array}{l}\text { ANTT, Chancelaria de D. Afonso V, liv. 15, fl. 144v; A. } \\
\text { H. de O. MARQUES, Introdução..., 45, 272-273; M. } \\
\text { J. P. F. TAVARES, Os sinais..., 507; S. C. } \\
\text { FERREIRA, Preços...,123-124 }\end{array}$ \\
\hline 1453 & $\mathrm{X}$ & Loulé & & $\begin{array}{l}\text { ANTT, Chancelaria de D. Afonso V, liv. 15, fl. 144v; A. } \\
\text { H. de O. MARQUES, Introdução...,45, 272-273; M. } \\
\text { J. P. F. TAVARES, Os sinais..., } 507\end{array}$ \\
\hline
\end{tabular}

«Alimentar la red urbana: las villas y ciudades portuarias del Algarve...» 


\begin{tabular}{|c|c|c|c|c|c|}
\hline 1454 & $\mathrm{X}$ & & Loulé & & $\begin{array}{l}\text { ANTT, Chancelaria de D. Afonso V, liv. 15, fl. 144v; A. } \\
\text { H. de O. MARQUES, Introdução..., 45, 272-273; M. } \\
\text { J. P. F. TAVARES, Os sinais..., 507; S. C. } \\
\text { FERREIRA, Preços..., 123-124 }\end{array}$ \\
\hline 1455 & $\mathrm{X}$ & & $\begin{array}{l}\text { Loulé, Tavira, } \\
\text { Faro }\end{array}$ & & $\begin{array}{l}\text { ANTT, Chancelaria de D. Afonso V, liv. 15, fl. 144v- } \\
145 \text { (Loulé, Tavira), 146-146v; A. H. de O. } \\
\text { MARQUES, Introdução..., 45, 272-273; M. J. P. F. } \\
\text { TAVARES, Os sinais..., 507; S. C. FERREIRA, } \\
\text { PreçOs...,123-124 }\end{array}$ \\
\hline 1459 & $\mathrm{X}$ & $\mathrm{X}$ & $\begin{array}{l}\text { Lagos, Tavira, } \\
\text { Silves }\end{array}$ & $\mathrm{X}$ & $\begin{array}{l}\text { ANTT, Chancelaria de D. Afonso V, liv. 36, fl. 114, } \\
\text { 169, 172; ANTT, Leitura Nova, Livro } 3 \text { do Guadiana, } \\
\text { fl. 84v; A. H. de O. MARQUES, Introdução..., 274; } \\
\text { S. C. FERREIRA, Preços..., 125; M. A. LADERO } \\
\text { QUESADA y M. GONZÁLEZ JIMÉNEZ, } \\
\text { Diezmo..., 46, } 117 \text {. }\end{array}$ \\
\hline 1460 & $\mathrm{X}$ & & & & $\begin{array}{l}\text { A. H. de O. MARQUES, Introdução..., 274; S. C. } \\
\text { FERREIRA, Preços...,125-126 }\end{array}$ \\
\hline 1462 & & & & $\mathrm{X}$ & $\begin{array}{l}\text { M. A. LADERO QUESADA y M. GONZÁLEZ } \\
\text { JIMÉNEZ, Diezmo...,46, } 117 \text {. }\end{array}$ \\
\hline 1463 & $\mathrm{X}$ & & & & S. C. FERREIRA, Preços..., 126 \\
\hline 1464 & $\mathrm{X}$ & & & & S. C. FERREIRA, Preços..., 126 \\
\hline 1466 & $\mathrm{X}$ & & & & S. C. FERREIRA, Preços..., 126 \\
\hline 1467 & & & & $\mathrm{X}$ & $\begin{array}{l}\text { M. A. LADERO QUESADA y M. GONZÁLEZ } \\
\text { JIMÉNEZ, Diezmo...,47-49, } 117 \text {. }\end{array}$ \\
\hline 1468 & $\mathrm{X}$ & & $\begin{array}{l}\text { Tavira, Loulé, } \\
\text { Faro, } \\
\text { Albufeira, } \\
\text { Lagos, Silves }\end{array}$ & $\mathrm{X}$ & $\begin{array}{l}\text { ANTT, Leitura Nova, Livro } 3 \text { do Guadiana, fl. 28v- } \\
\text { 29; ANTT, Chancelaria de D. João II, liv. 8, fl. 199- } \\
\text { 199v; Actas de Vereação de Loulé. Séculos XIV-XV, 204, } \\
\text { 210; A. H. de O. MARQUES, Introdução..., 45, M. J. } \\
\text { P. F. TAVARES, Os sinais..., 507; S. C. FERREIRA, } \\
\text { Preços..., 127; M. A. LADERO QUESADA y M. } \\
\text { GONZÁLEZ JIMÉNEZ, Diezmo..., 47-49, } 117 \text {. }\end{array}$ \\
\hline 1469 & $\mathrm{X}$ & & & & $\begin{array}{l}\text { A. H. de O. MARQUES, Introdução..., 45, M. J. P. } \\
\text { F. TAVARES, Os sinais...,507 }\end{array}$ \\
\hline 1470 & $\mathrm{X}$ & & & & $\begin{array}{l}\text { A. H. de O. MARQUES, Introdução..., 45, M. J. P. } \\
\text { F. TAVARES, Os sinais..., } 507\end{array}$ \\
\hline 1471 & & & $\begin{array}{l}\text { Loulé, Lagos, } \\
\text { Silves }\end{array}$ & & $\begin{array}{l}\text { ANTT, Chancelaria de D. Afonso V, liv. 22, fl. 132v; y } \\
\text { liv. 29-30v }\end{array}$ \\
\hline 1472 & $\mathrm{X}$ & & & & A. H. de O. MARQUES, Introdução..., 275 \\
\hline 1473 & $\mathrm{X}$ & & Tavira & $\mathrm{X}$ & $\begin{array}{l}\text { ANTT, Chancelaria de D. Afonso V, liv. 33, fl. } 219 \\
\text { A. H. de O. MARQUES, Introdução...,275;S. C. } \\
\text { FERREIRA, Preços..., 128-129; M. A QUESADA y } \\
\text { M. GONZÁLEZ JIMEENEZ, Diezmo...81-83, } 117 .\end{array}$ \\
\hline 1474 & & & & $\mathrm{X}$ & $\begin{array}{l}\text { M. A. LADERO QUESADA y M. GONZÁLEZ } \\
\text { JIMÉNEZ, Diezmo...,81-83, } 117 .\end{array}$ \\
\hline 1475 & $\mathrm{X}$ & & & & $\begin{array}{l}\text { A. H. de O. MARQUES, Introdução..., 275-277; S. } \\
\text { C. FERREIRA, Preços...,128-129 }\end{array}$ \\
\hline 1476 & $\mathrm{X}$ & & & & $\begin{array}{l}\text { A. H. de O. MARQUES, Introdução...275-277; S. C. } \\
\text { FERREIRA, Preços...,129-131 }\end{array}$ \\
\hline 1477 & $\mathrm{X}$ & $\mathrm{X}$ & Tavira & & $\begin{array}{l}\text { ANTT, Cortes, maço 2, no 14, fls. 142-142v ; BACL, } \\
\text { Reservados, Série Azul, t 402, fl. 141-141v; A. H. de O. } \\
\text { MARQUES, Introdução..., 275-277; S. C. }\end{array}$ \\
\hline
\end{tabular}




\begin{tabular}{|c|c|c|c|c|}
\hline & & & & FERREIRA, Preços..., 129-131 \\
\hline 1478 & $\mathrm{X}$ & Tavira & $\mathrm{X}$ & $\begin{array}{l}\text { ANTT, Leitura Nova, Livro } 5 \text { do Guadiana, fl. 113v- } \\
114 \quad \text { (Tavira); A. H. de O. MARQUES, } \\
\text { Introdução...,275-277; S. S C. FERREIRA, } \\
\text { Preços...,129-131; M. A. LADERO QUESADA y M. } \\
\text { GONZÁLEZ JIMÉNEZ, Diezmo..., } \\
\text { G3-85, } 117 .\end{array}$ \\
\hline 1479 & $\mathrm{X}$ & & & S. C. FERREIRA, Preços...,131 \\
\hline 1480 & $\mathrm{X}$ & & & $\begin{array}{l}\text { A. H. de O. MARQUES, Introdução..., 45, M. J. P. } \\
\text { F. TAVARES, Os sinais..., 508;S. C. FERREIRA, } \\
\text { Preços..., } 131\end{array}$ \\
\hline 1481 & $\mathrm{X}$ & & & S. C. FERREIRA, Preços..., 131 \\
\hline 1482 & $\mathrm{X}$ & Lagos & & $\begin{array}{llllll}\text { Descobrimentos Portugueses, } & \text { III, } & 636-637 ; & \text { S. } & \text { C. } \\
\text { FERREIRA, Precos... } 132 & & & & \end{array}$ \\
\hline 1483 & $\mathrm{X}$ & & & S. C. FERREIRA, Preços...,132 \\
\hline 1484 & $\mathrm{X}$ & & & $\begin{array}{l}\text { A. H. de O. MARQUES, Introdução..., 45, 277-279; } \\
\text { M. J. P. F. TAVARES, Os sinais..., 508; S. C. } \\
\text { FERREIRA, Preços..., 132-138 }\end{array}$ \\
\hline 1485 & $\mathrm{X}$ & & & $\begin{array}{l}\text { A. H. de O. MARQUES, Introdução..., 45, 277-279; } \\
\text { M. J. P. F. TAVARES, Os sinais..., 508; S. C. } \\
\text { FERREIRA, Preços... 132-138 }\end{array}$ \\
\hline 1486 & $\mathrm{X}$ & $\begin{array}{l}\text { Loulé, } \\
\text { Albufeira, } \\
\text { Lagos (?), } \\
\text { Faro (?), } \\
\text { Tavira (?), } \\
\text { Silves (?) }\end{array}$ & $\mathrm{X}$ & $\begin{array}{l}\text { A. H. de O. MARQUES, Introdução..., 45,277-27; } \\
\text { M. J. P. F. TAVARES, Os sinais..., 509; S. C. } \\
\text { FERREIRA, Preços..., 132-138; M. A. LADERO } \\
\text { QUESADA y M. GONZÁLEZ JIMÉNEZ, } \\
\text { Diezmo..., 85-86, 117; ANTT, Chancelaria de D. João } \\
\text { II, liv. 8, fl. 180; ANTT, Chancelaria de D. João II, liv. } \\
\text { 8, fl. } 199\end{array}$ \\
\hline 1487 & $\mathrm{X}$ & Loulé & & $\begin{array}{l}\text { Actas de Vereação de Loulé. Séculos XIV-XV, 223-224; } \\
\text { A. H. de O. MARQUES, Introdução..., 45, 277-279 } \\
\text { M. J. P. F. TAVARES, Os sinais..., 509; S. C. } \\
\text { FERREIRA, Preços..., 132-138 }\end{array}$ \\
\hline 1488 & $\mathrm{X}$ & & & $\begin{array}{l}\text { A. H. de O. MARQUES, Introdução..., 45, 277-279 } \\
\text { M. J. P. F. TAVARES, Os sinais..., } 509\end{array}$ \\
\hline 1489 & & & $\mathrm{X}$ & $\begin{array}{l}\text { M. A. LADERO QUESADA y M. GONZÁLEZ } \\
\text { JIMÉNEZ, Diezmo..., 83-85, } 117 \text {. }\end{array}$ \\
\hline 1490 & & Lagos & & Descobrimentos Portugueses, Vol. III,363 \\
\hline 1490 & $\mathrm{X}$ & Lagos & & $\begin{array}{l}\text { A. H. de O. MARQUES, Introdução..., 45, 279-280; } \\
\text { M. J. P. F. TAVARES, Os sinais..., 509; } \\
\text { Descobrimentos Portugueses, Vol. III, 364; S. C. } \\
\text { FERREIRA, Preços, Salários e Níveis de Vida..., pp. } \\
\text { 139-140 }\end{array}$ \\
\hline 1491 & $\mathrm{X}$ & & & $\begin{array}{l}\text { A. H. de O. MARQUES, Introdução..., 45, 279-280; } \\
\text { M. J. P. F. TAVARES, Os sinais..., 509; S. C. } \\
\text { FERREIRA, Preços..., pp. } 140-146\end{array}$ \\
\hline 1494 & $\mathrm{X}$ & & & $\begin{array}{l}\text { A. H. de O. MARQUES, Introdução..., 45, 280-282; } \\
\text { M. J. P. F. TAVARES, Os sinais..., 509; S. C. } \\
\text { FERREIRA, Preços..., 140-146 }\end{array}$ \\
\hline 1495 & $\mathrm{X}$ & Loulé & & $\begin{array}{l}\text { A. H. de O. MARQUES, Introdução..., 45, 280-282; } \\
\text { M. J. P. F. TAVARES, Os sinais dos tempos..., 509; } \\
\text { Actas de Vereação de Loulé. Século XV, pp. 187, 189; S. } \\
\text { C. FERREIRA, Preços..., 140-146 }\end{array}$ \\
\hline 1496 & $\mathrm{X}$ & Tavira & & ANTT, Leitura Nova, Livro 4 do Guadiana, fl. $287 \mathrm{v}-$ \\
\hline
\end{tabular}

«Alimentar la red urbana: las villas y ciudades portuarias del Algarve...» 


\begin{tabular}{|c|c|c|c|c|}
\hline & & & & $\begin{array}{l}288 \text { (Tavira); A. H. de O. MARQUES, Introdução..., } \\
\text { 45, 280-282; M. J. P. F. TAVARES, Os sinais..., 509 }\end{array}$ \\
\hline 1498 & $\mathrm{X}$ & Faro, Lagos & & $\begin{array}{l}\text { Cortes Portuguesas: Reinado de D. Manuel I (Cortes de } \\
\text { 1498), 406, 419. M. J. P. F. TAVARES, Os sinais..., } \\
510\end{array}$ \\
\hline 1503 & & & $\mathrm{X}$ & $\begin{array}{l}\text { M. A. LADERO QUESADA y M. GONZÁLEZ } \\
\text { JIMÉNEZ, Diezmo eclesiástico..., 89-91, 117; E. } \\
\text { GUITÉRREZ MARTÍN, La crisis..., 278. }\end{array}$ \\
\hline 1504 & $X$ & Tavira & $X$ & $\begin{array}{l}\text { ANTT, Chancelaria de D. Manuel I, liv. 44, fl. 122v, } \\
\text { 125; M. J. P. F. TAVARES, Os sinais...,510; E. } \\
\text { GUITÉRREZ MARTÍN, La crisis..., 278. }\end{array}$ \\
\hline 1505 & $\mathrm{X}$ & & $\mathrm{X}$ & $\begin{array}{l}\text { M. J. P. F. TAVARES, Os sinais...,510; E. } \\
\text { GUITÉRREZ MARTÍN, La crisis...,278. }\end{array}$ \\
\hline 1506 & $\mathrm{X}$ & & $\mathrm{X}$ & $\begin{array}{l}\text { M. J. P. F. TAVARES, Os sinais dos tempos..., 510; } \\
\text { E. GUITÉRREZ MARTÍN, La crisis..., } 278 .\end{array}$ \\
\hline 1507 & $\mathrm{X}$ & & $\mathrm{X}$ & $\begin{array}{l}\text { M. J. P. F. TAVARES, Os sinais..., 510; E. } \\
\text { GUITÉRREZ MARTÍN, Las crisis..., } 78 .\end{array}$ \\
\hline 1508 & $\mathrm{X}$ & & & M. J. P. F. TAVARES, Os sinais...,510 \\
\hline 1516 & $\mathrm{X}$ & & & M. J. P. F. TAVARES, Os sinais...,510 \\
\hline 1521 & $\mathrm{X}$ & & $\mathrm{X}$ & $\begin{array}{l}\text { M. J. P. F. TAVARES, Os sinais..., 511; E. } \\
\text { GUITÉRREZ MARTÍN, La crisis..., } 278 .\end{array}$ \\
\hline
\end{tabular}

Figura 2. Referencias a crisis alimetarias en Portugal, Algarve e Andaluzia

$$
\text { (1302-1521) }
$$

Leyenda: Pt: Portugal; Al: Algarve; An: Andalucía 


\section{Bibliografía}

\section{Fuentes publicadas}

A. IRIA, O Algarve nas cortes medievais portuguesas do século XIV (subsidios para a sua história). Lisboa 1982.

A. IRIA, O Algarve nas cortes medievais portuguesas do século XV, subsídios para a sua bistória (1404-1449), Lisboa 1990.

Actas de Vereação de Loulé. Século XV. Separata da Al'-ulyã: Revista do Arquivo Histórico Municipal de Loulé, Loulé 2004.

Actas de Vereaşão de Loulé. Séculos XIV-XV = Actas de Vereação de Loulé. Séculos XIV-XV, Separata da Al'-ulyã: Revista do Arquivo Histórico Municipal de Loulé. Loulé: Arquivo Municipal de Loulé, 1999-2000.

Chancelarias portuguesas: D. Afonso IV, org. A. H. de O. MArQues, 3 vols. Lisboa 1990-1992.

Chancelarias Portuguesas: D. João I., edição preparada por J. J. A. DIAS, 4 vols., Lisboa 2004-2006.

Cortes Portuguesas: Reinado de D. Fernando I (1367-1383), edición preparada por A. H. de O. MARQUeS e N. J. P. P. Dias, vol. I: 1367-1380, Lisboa 1990.

Cortes Portuguesas: Reinado de D. Manuel I (Cortes de 1498). Organización y revisión general por J. J. A. DIAS, Lisboa 2002.

F. C. BELotO, Pharonensia Monumenta Historica III», Anais do Municipio de Faro, VI, 1976, 213-223.

F. C. BELOTO, «Pharonensia Monumenta Historica IV - Documentos do século XV, Anais do Município de Faro. VII, 1977, 221-229.

F. C. Beloto, «Pharonensia Monumenta Historica V - Documentos do século XV», Anais do Município de Faro. IX, 1979, 321-326

História florestal, aquicola e cinegética. Colectânea de documentos existentes no Arquivo Nacional da Torre do Tombo. Chancelarias reais. Ed. C. B. das NEVES, VI vols. Lisboa 1982.

J. M. da S. MARQUeS, (dirs.), Descobrimentos Portugueses. Documentos para a sua História. $2^{\mathrm{a}}$ ed., 4 Vols. Lisboa 1988.

J. R. de Magalhães y M. V. Guerreiro (eds.), Duas Descrições do Algarve do Século XVI, Lisboa 1983.

Livro do Almoxarifado de Silves (século XV), prefácio H. B. MORENO, identificação e transcrição de M. J. da S. LEAL; notas, observações e comentários de J. G. DOMINGUES, Lisboa 1984.

«Alimentar la red urbana: las villas y ciudades portuarias del Algarve...» 
Visconde de Santarém, Alguns documentos para servirem de provas à parte $1^{a}$ das memorias para a história, e theoria das cortes gerias, que em Portugal se celebrarão pelos três estados do reino ordenadas no anno de 1824. Lisboa 1828

\section{Estudios}

A. H. de O. MARQues, Introdução à história da agricultura em Portugal. A questão cerealífera durante a Idade Média. Lisboa 1968.

A. H. de O. Marques, Portugal na Crise dos Séculos XIV e XV, vol. IV da Nova História de Portugal, J. SERRAO y A. H. de O. MARQUES, (Dirs.), Lisboa 1987

A. M. Rodrigues, «The Black Death and Recovery, 1348-1500», en Dulce FreIRE y P. LAINS (eds.), An agrarian history of Portugal, 10002000: economic development on the European frontier, Leiden, Boston, 2017, 45-68.

A. REIRA i MELIS, «Crisis frumentarias y políticas municipales de abastecimiento en las ciudades catalanas durante la Baja Edad Media», en H. R. Oliva Herrer y P. Benito i Monclús (coord.), Crisis de subsistencia y crisis agrarias en la Edad Media, Sevilla 2007, 125-160.

A. REIRA i MELIS, «Tener siempre bien aprovisionada la población: los cereales y el pan en las ciudades catalanas durante la Baja Edad Media», en B. Arízaga Bolumburu y J. Solórzano Telechea (coord.), Alimentar la ciudad en la Edad Media. Logroño 2009, p. 23-58.

F. MENANT, «Crisis de subsistencia y crisis agrarias en la Edad Media: algunas reflexiones previas», en H. R. OlIVA HERRER y P. BENITO I MONCLÚs (coord.), Crisis de subsistencia y crisis agrarias en la Edad Media. Sevilha 2007, 17-60.

G. M. da SILVA, «A Coroa, as vilas e o mar: A rede urbana portuária do Algarve (1266-1325) », en Adelaide Millán da CosTA et al., O papel das pequenas cidades na construção da Europa Medieval, Lisboa 2017, 507-535.

G. M. da SilvA, «Un poder que viene del Mar Océano: las Cofradías de los Hombres del Mar en el Algarve a fines de la Edad Media», en J. SOLÓRZANO TELECHEA et al. (eds.), Las sociedades portuarias de la Europa Atlántica en la Edad Media. Logroño 2016, 115-135.

E. GutiÉrREZ MARTíN, «La crisis de 1503-1507 en Andalucía: reflexiones a partir de Jerez de La Frontera», en H. R. Oliva Herrer y P. BENITO I MONClús (coord.), Crisis de subsistencia y crisis agrarias en la Edad Media. Sevilha 2007, 277-302. 
H. R. Oliva Herrer, «Carestía y lucha política en Castilla durante el siglo XV», Anuario de Estudios Medievales. 46, 2, 2016, 899-937.

I. GonÇALVES, À mesa nas terras de Alcobaça em finais da Idade Média. Alcobaça 2017.

I. GONÇALVES, «A propósito do pão da cidade na Baixa Idade Média», en C. G. da SILVA (coord.), Turres Veteras IX. História da Alimentação. Torres Vedras 2007, 49- 72.

I. GONÇALVES, «Defesa do consumidor na cidade medieval: os produtos alimentares (Lisboa - séculos XIV e XV)», Um olhar sobre a cidade medieval. Cascais 1996, $97-116$.

J. L. Villalonga SERRANO, "Crisis y endeudamiento en la campiña sevillana a finales de la Edad Media», en H. R. Oliva Herrer y P. BENITO I MONCLÚs (coord.), Crisis de subsistencia y crisis agrarias en la Edad Media. Sevilha 2007, 331-357.

J. R. Magalhaes, Para o estudo Algarve económico durante o século XVI. Lisboa 1970.

L. A. da Fonseca y J. A. S. M. PIZARro, «Algumas considerações sobre o comércio externo algarvio na época medieval», en Actas das I Jornadas de História Medieval do Algarve e Andaluria. Loulé: UAlg 1987, 61-89.

L. A. da FONSECA, «O Algarve da Reconquista à conjuntura depressiva do século XIV», en M. da G. MARQUES (dir.), O Algarve da antiguidade aos nossos dias: elementos para a sua história. Lisboa 1999, 115-122.

L. Palermo; A. Fara y P. Benito i Monclús (coords.), Políticas contra el hambre y la carestía en la Europa medieval. Lleida 2018.

L. PAlermo, «Di fronte alla crisi: l'economia e il linguaggio della carestia nelle fonti medieval», en P. BENITO I MONCLÚs (coord.), Crisis alimentarias en la Edad Media: modelos, explicaciones y representaciones, Lleida 2013, 47-67.

M. Â. BEIRANTE, «Relações entre o homem e a natureza nas mais antigas posturas da câmara de Loulé (séculos XIV-XV)», en Actas das I Jornadas de História Medieval do Algarve e Andaluria, Loulé 1987, 231-242

M. A. LADERO QueSADA y M. GONZÁLEZ JIMÉNEZ, Dieżmo eclesiástico y producción de cereales en reino de Sevilla: 1408-1503, Sevilla 1979.

M. BORRERO FERNÁNDEZ, «Propiedad campesina y crisis agrarias: Andalucía a principios del siglo XVI», en H. R. Oliva Herrer y P. BENITO I MONCLÚs (coord.), Crisis de subsistencia y crisis agrarias en la Edad Media, Sevilha 2007, 303-330.

«Alimentar la red urbana: las villas y ciudades portuarias del Algarve...» 
M. de F. BOTAO, A construção de uma identidade urbana no Algarve medieval. $O$ caso de Loulé. Casal da Cambra 2009.

M. H. da C. Coelho, O Baixo Mondego nos finais da Idade Média, Lisboa 1989, 2 vols.

M. J. P. F. TAvares, «Os sinais dos tempos: Para o estudo do clima e do litoral português», in A. A. TAVARES et al. (eds.), Evolução geohistórica do litoral português e fenómenos correlativos: geologia, história, arqueologia e climatologia, Lisboa 2004, 451-515.

M. T. MalteZ, Os recursos alimentares no Algarve Oriental (século XIV). Lisboa: s.n., 1993, Dissertação de mestrado em História Medieval apresentada à FCSH/UNL, policopiada.

P. BENITO I MONCLÚS, «De Labrousse a Sen. Modelos de causalidad y paradigmas interpretativos de las crisis alimentarias preindustriales», en P. Benito i Monclús (coord.), Crisis alimentarias en la Edad Media: modelos, explicaciones y representaciones. Lleida 2013, 47-67.

P. BENITO I MONCLÚS, «Fams i caresties a la Mediterrània occidental durant la baixa edat mitjana: el debat sobre "les crisis de la crisi"», Recerques: Història, economia i cultura, 49, 2004, 179-193.

P. BENito I MONCLÚs, «Las crisis alimenticias en la Edad Media: carácteres generales, distinciones y paradigmas interpretativos», en E. LÓPEZ OJEDA, Comer, beber, vivir: consumo y niveles de vida en la Edad Media Hispánica, Logroño 2011.

S. C. Ferreira, Preços, Salários e Niveis de Vida em Portugal na Baixa Idade Média. Porto: s.n, 2014, Doutoramento em História apresentado à FLUP, policopiado.

V. RAU, Sesmarias medievais portuguesas, Lisboa 1982. 